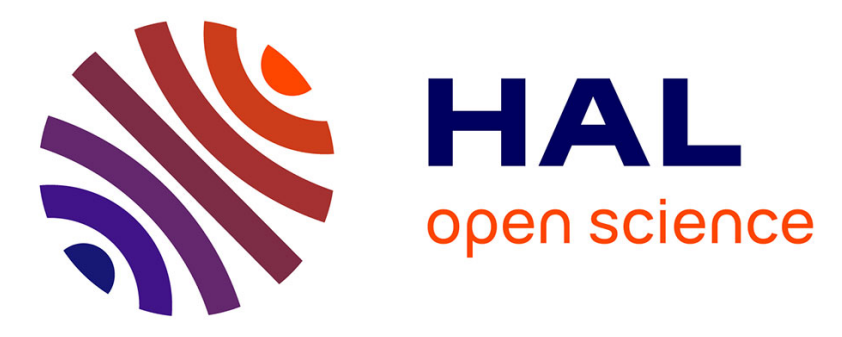

\title{
Brain metabolic abnormalities during gait with freezing in Parkinson's disease
}

Céline Tard, Arnaud Delval, David Devos, Renaud Lopes, Pierre Lenfant, Kathy Dujardin, Claude Hossein-Foucher, Franck Semah, Alain Duhamel, Luc Defebvre, et al.

\section{To cite this version:}

Céline Tard, Arnaud Delval, David Devos, Renaud Lopes, Pierre Lenfant, et al.. Brain metabolic abnormalities during gait with freezing in Parkinson's disease. Neuroscience, 2015, 307, pp.281-301. 10.1016/j.neuroscience.2015.08.063 . hal-01195740

\section{HAL Id: hal-01195740 \\ https://hal-univ-rennes1.archives-ouvertes.fr/hal-01195740}

Submitted on 2 Dec 2015

HAL is a multi-disciplinary open access archive for the deposit and dissemination of scientific research documents, whether they are published or not. The documents may come from teaching and research institutions in France or abroad, or from public or private research centers.
L'archive ouverte pluridisciplinaire HAL, est destinée au dépôt et à la diffusion de documents scientifiques de niveau recherche, publiés ou non, émanant des établissements d'enseignement et de recherche français ou étrangers, des laboratoires publics ou privés. 


\section{Brain metabolic abnormalities during gait with freezing in Parkinson's}

\section{disease}

Céline Tard ${ }^{\mathrm{a}, \mathrm{b}}$, Arnaud Delval ${ }^{\mathrm{a}, \mathrm{b}}$, David Devos ${ }^{\mathrm{a}-\mathrm{c}}$, Renaud Lopes ${ }^{\mathrm{b}, \mathrm{d}}$, Pierre Lenfant ${ }^{\mathrm{e}}$, Kathy Dujardin $^{\mathrm{a}, \mathrm{b}}$, Claude Hossein-Foucher ${ }^{\mathrm{e}}$, Franck Semah ${ }^{\mathrm{b}, \mathrm{e}}$, Alain Duhamel ${ }^{\mathrm{f}}$, Luc Defebvre ${ }^{\mathrm{a}, \mathrm{b}}$, Florence Le Jeune ${ }^{\mathrm{g}}$, Caroline Moreau ${ }^{\mathrm{a}, \mathrm{b}}$

${ }^{\text {a }}$ Service de Neurologie et Pathologie du mouvement, Hôpital Roger Salengro, CHRU de Lille, Lille, France

${ }^{\mathrm{b}}$ U1171, Université Lille, Lille, France

${ }^{c}$ Service de Pharmacologie médicale, Faculté de Médecine Lille, CHRU de Lille, Lille, France

${ }^{\mathrm{d}}$ Service de Neuroradiologie clinique, Hôpital Roger Salengro, CHRU de Lille, Lille, France

${ }^{\text {e }}$ Service de Médecine Nucléaire, Hôpital Roger Salengro, CHRU de Lille, Lille, France

${ }^{\mathrm{f}}$ Service de Biostatistiques de santé publique, CHRU de Lille, Lille, France

${ }^{\mathrm{g}}$ Service de Médecine Nucléaire, Centre Eugène Marquis, Rennes, France

Corresponding author: Céline Tard MD

Neurologie et Pathologie du Mouvement, Neurologie A, Hôpital Salengro, Centre Hospitalier Universitaire, F-59037 Lille Cedex, France

Tel.: + 33320446751

Fax: + 33320446680

E-mail: celinetard@gmail.com

Word count: 7810 
Freezing of gait in PD: brain metabolism

Running-title: Freezing of gait in PD: brain metabolism

Key-words: PET, associative somatosensory cortex, premotor cortex, temporopolar area, executive-attention network

Disclosure/Conflict of Interest: None

\section{ABSTRACT}

Introduction: Freezing of gait $(\mathrm{FoG})$ is a debilitating gait disorder in Parkinson's disease (PD). In advanced PD patients with FoG, the supraspinal locomotor network may be dysregulated (relative to similar patients without FoG) during gait. Here, we sought to characterize the metabolism of locomotor networks involved in FoG.

Methods: Twenty-two PD patients (11 with off-drug FoG and 11 without) each underwent two $\left[{ }^{18} \mathrm{~F}\right]$-fluorodeoxyglucose PET brain scans in the off-drug state: one at rest and another during radiotracer uptake while performing a standardized gait trajectory that incorporated the usual triggers for FoG.

Results: For the 11 freezers, FoG was present for $39 \%( \pm 23 \%)$ of the time during the gait trajectory. The FoG-associated abnormalities were characterized by (i) hypometabolism in frontal regions (the associative premotor, temporopolar and orbitofrontal areas, i.e. Brodmann areas 6 and 8), (ii) hypermetabolism in the paracentral lobule (Brodmann area 5), and (iii) deregulation of the basal ganglia output (the globus pallidus and the mesencephalic locomotor region).

Conclusion: FoG during a real gait task was associated with impaired frontoparietal cortical activation, as characterized by abnormally low metabolic activity of the premotor area (involved in the indirect locomotor pathway) and abnormally high metabolic activity of the parietal area (reflecting the harmful effect of external cueing). 
Freezing of gait in PD: brain metabolism

\section{Abbreviations}

$\left[{ }^{18} \mathrm{~F}\right]$-FDG-PET: $\left[{ }^{18} \mathrm{~F}\right]$-fluorodeoxyglucose positron emission tomography

FEF: frontal eye field

FoG: freezing of gait

MLR: mesencephalic locomotor region

SMA: supplementary motor area

PD: Parkinson's disease

ROI: region of interest 


\section{INTRODUCTION}

Freezing of gait (FoG) is defined as a brief, episodic absence or marked reduction of forward progression of the feet despite the intention to walk (Nutt et al., 2011). This phenomenon affects about three quarters of people with Parkinson's disease (PD) (Macht et al., 2007). Dopaminergic medications do not alleviate FoG in $15 \%$ of patients and produce only partial relief in $44 \%$ of patients (Perez-Lloret et al., 2014). Even though severe dopaminergic striatal denervation has been described in models of freezing (even in other parkinsonian syndromes than in idiopathic PD (Park et al., 2009)), imaging studies of patients with PD have shown that the mechanism of FoG also involves non-dopaminergic pathways (Bartels et al., 2006). A better understanding of the neural basis of FoG would probably boost the development of effective therapeutic approaches.

The variable, episodic nature of FoG makes it difficult to study this phenomenon in the laboratory (Schaafsma et al., 2003; Snijders et al., 2008). Furthermore, imaging studies of FoG are technically complex because the freezing occurs during gait (i.e. when the person in the vertical position, rather than in the horizontal position required for concomitant MRI acquisition) (Bartels and Leenders, 2008; Maillet et al., 2012; Herman et al., 2013; Shine et al., 2013d). Recently, researchers have found new ways of studying FoG by using mental imagery of gait (Snijders et al., 2011; Crémers et al., 2012; Maillet et al., 2015; Peterson et al., 2014a, 2014b) and virtual reality tasks (Shine et al., 2013a, 2013b, 2013c; Shine et al., 2011b). Other functional MRI approaches are based on creating the equivalent of FoG for the upper limbs (Vercruysse et al., 2014a) or performing alternating foot movements in the supine position (Shine et al., 2013a, 2013b, 2013c; Shine et al., 2011b) in order to individualize motor blocks that could be time-locked with changes in brain perfusion. These experiments evidenced corticosubcortical decoupling during freezing, with (i) 
Freezing of gait in PD: brain metabolism

hypoactivation of the basal ganglia, thalamus and sensorimotor regions and (ii) hyperactivation of the frontoparietal cortical regions (Shine et al., 2013a; Vercruysse et al., 2014a). Namely, the Brodmann area 6 -including SMA (Snijders et al., 2011; Vercruysse et al., 2014a; Maillet et al., 2015), the pre-SMA (Shine et al., 2013b) and the dorsolateral prefrontal cortex (Vercruysse et al., 2014a)-, is of interest because it is known to be directly involved in locomotor networks used to compensate for gait impairment in patients with PD (Snijders et al., 2011; Shine et al., 2013b; Vercruysse et al., 2014b; Peterson et al., 2014b), potentially via the hyper-direct pathway from the pre-SMA to the STN (Shine et al., 2013d), However, mental imagery and virtual reality do not fully reflect "real life" conditions because (i) the patient's ability to imagine him/herself performing gait may vary (Cohen et al., 2011; van der Meulen et al., 2014) and (ii) the supine position required for MRI is not physiologically normal for gait because it fails to simulate movement of the centre of gravity during movement (Massion, 1992; Karim et al., 2014).

Otherwise, network-based hypotheses have been tested by using (i) diffusion tensor imaging to study anatomic disconnection (and particularly disconnection from the pedunculopontine nucleus) (Schweder et al., 2010; Tessitore et al., 2012b; Fling et al., 2013; Peterson et al., 2015; Youn et al., 2015) and (ii) the blood-oxygen-level-dependent signal to assess functional reorganization of the default mode and locomotor networks (Pappatà et al., 2011; Tessitore et al., 2012b; Fling et al., 2014; for reviews, see Bartels and Leenders, 2008; Maillet et al., 2012; Herman et al., 2013; Vercruysse et al., 2014a). Lastly, brain atrophy has been measured in patients with FoG, with divergent results (Tessitore et al., 2012a; Sunwoo et al., 2013; Rubino et al., 2014); this may be related to the fact that FoG is frequently associated with cognitive impairment (Herman et al., 2014). Furthermore, cognitive dysfunction can modify brain metabolism (Bohnen et al., 2011; Pappatà et al., 2011). Thus, it is important to recruit non-demented, cognitively matched 
Freezing of gait in PD: brain metabolism

patients to better understand the pathophysiology of FoG itself and avoid potential confounding aspects as attentional or executive impairment, that are often linked with FoG (Yogev-Seligmann et al., 2008; Vandenbossche et al., 2011).

In the present study, we adopted a strategy based on current hypotheses about FoG (Nutt et al., 2011; Nieuwboer and Giladi, 2013). In fact, FoG appears to be just one of several abnormalities that occur during continuous gait (Hausdorff et al., 2003; Chee et al., 2009; Vercruysse et al., 2012), including start hesitation (Schaafsma et al., 2003), trembling in place (Schaafsma et al., 2003), sequence effects (Chee et al., 2009) and elevated step variability (Hausdorff et al., 2003). Hence, the gait impairments in patients with FoG are probably more complex than the FoG phenomenon itself since they encompass FoG episodes. Some mental imaging protocols have studied gait disorders in general in freezers (Snijders et al., 2011; Crémers et al., 2012; Maillet et al., 2015). In order to dissociate gait abnormalities and FoG phenomenon, restrictive FoG-time-locked imaging studies have also been performed (Shine et al., 2013a, 2013b), but might therefore fail to observe fundamental metabolic impairments in freezers during gait (Nutt et al., 2011; Nieuwboer and Giladi, 2013; Shine et al., 2013d).

We used here a technique based on the measurement of glucose uptake (a proxy marker for brain metabolism) that has already been used to study (i) gait disorders in progressive supranuclear palsy (Zwergal et al., 2013) and (ii) pure akinesia with gait freezing (Park et al., 2009). Positron emission tomography (PET) of $\left[{ }^{18} \mathrm{~F}\right]$-fluorodeoxyglucose $\left(\left[{ }^{18} \mathrm{~F}\right]-\mathrm{FDG}\right.$, a glucose analogue that can cross the blood-brain barrier) is known to reflect the brain cells' metabolism over the 20 to 30 minutes following the injection of the radiotracer. The subsequent stabilization of radiotracer levels enables image acquisition after this timepoint. Hence, if the subject performs actual gait in the 30 minutes following injection of $\left[{ }^{18} \mathrm{~F}\right]$ - 
FDG, uptake of the radiotracer will reflect the brain's metabolism during this motor activity, making it a real activation imaging (la Fougère et al., 2010). In the present study, we explored the brain's metabolism during gait with FoG by comparing two matched populations of non-demented PD patients presenting (or not) off-drug FoG during a standardized, 30-minute series of FoG-triggering gait trajectories (referred to hereafter as the "FoG trajectories") (Snijders et al., 2008). We then compared brain activation at rest with brain activation immediately after performance of the FoG trajectories (i.e. reflecting metabolism during uptake of the radiotracer).

We hypothesized that compensatory locomotor networks, involving namely the SMA, could be recruited during this high-level gait task in the non-freezers patients, whereas freezers patients could display less activation of this area. Concerning the subcortical structures (basal ganglia and mesencephalic locomotor region -MLR-), we hypothesized that gait with a real load and intensive proprioceptive afferences could modify the data previously determined by fMRI (Dietz et al., 2002). Finally, we expected a potential deregulation of the compensatory networks in freezers patients.

\section{METHODS}

\subsection{Subjects}

We recruited a group of PD patients with FoG in the off-drug condition (Schaafsma et al., 2003) (the FoG group, $n=11$ ) and a matched group of PD patients without FoG (the nonFoG group, $\mathrm{n}=11$ ). The study's objectives and procedures were approved by the local investigational review board. Each participant gave his/her written consent to participation in the study.

Twenty-two outpatients with PD diagnosed according to Gibb's criteria (1988) were enrolled from the active case file of the Movement Disorders Department at Lille 
Freezing of gait in PD: brain metabolism

University Hospital (Lille, France). We first screened PD patients with off-drug FoG (Schaafsma et al., 2003; Espay et al., 2012) (forming the FoG group) on the basis of their answer to item 3 of the FoG questionnaire (Giladi et al., 2009). We next checked that potentially eligible patients displayed FoG episodes during specific FoG trajectories (Snijders et al., 2008) in the off-drug state but not in the "supra-on-drug" state (i.e. after an acute intake of at least one and a half times the usual dose of levodopa) (Schaafsma et al., 2003; Espay et al., 2012). We then included non-freezer PD patients matched for age, gender, cognitive efficiency (according to the Mattis Dementia Rating Scale (Schmidt et al., 1994; Green et al., 1995)) and overall motor severity, in order to form the non-FoG group. The exclusion criteria included the inability to walk unaided in the off-drug condition, the use of deep brain stimulation, the presence of neurological disorders other than PD, dementia (as defined by the Movement Disorders Society criteria (Emre et al., 2007) and by a Mattis Dementia Rating Scale score of 130 or less out of 144 recorded in the 6 months preceding the PET acquisition (Schmidt et al., 1994)) and major depression (according to the DSM IV criteria (American Psychiatric Association., 1994)). To ensure that all FoG episodes were dopasensitive, patients not taking dopaminergic medications as part of their usual therapeutic regimen were excluded from the study. Neuropsychological assessments were performed in on-drug state, including Mini Mental State Examination (Folstein et al., 1975), Mattis Dementia Rating Scale (Green et al., 1995), Hamilton Anxiety Scale (Hamilton, 1959), Montgomery and Asberg Depression Rating Scale (Montgomery and Asberg, 1979) and Lille Apathy Rating Scale (Sockeel et al., 2006) (Table 1).

Although clinical evaluations and PET scans were performed under off-drug conditions, the participants had been on their usual, stable medication regimen for at least 3 months prior to inclusion. 


\subsection{Experimental design}

Clinical observations and nuclear medicine procedures were all performed under off-drug conditions (i.e. after the withdrawal of dopaminergic therapy for at least 12 hours) (Langston et al., 1992).

We evaluated the brain's metabolism of $\left[{ }^{18} \mathrm{~F}\right]-\mathrm{FDG}$ first at rest and then immediately after continuous gait performed during radiotracer uptake. The time interval between these two acquisitions was between one and four weeks. In the resting condition, the participant lay still in the supine position throughout the 30-minute tracer uptake and stabilization period. A 15-minute PET scan was then performed. In the gait condition, the participant performed

FoG trajectories (Snijders et al., 2008) for the 30 minutes immediately following the injection of $\left[{ }^{18} \mathrm{~F}\right]-\mathrm{FDG}$ (i.e. during radiotracer uptake and stabilization). The subsequent 15-minute emission scan reflected brain metabolism during the FoG trajectories.

Actual gait was performed for 30 minutes before the PET acquisition because this corresponds to the time required for $\left[{ }^{18} \mathrm{~F}\right]-\mathrm{FDG}$ uptake and stabilization in the brain (Lucignani et al., 1993; Shimoji et al., 2004). The patient performed the FoG trajectories (Snijders et al., 2008) throughout the radiotracer uptake period, so that environmental triggers elicited as many FoG episodes as possible.

The FoG trajectory was standardized, as previously described by Snijders et al. (2008): all patients initiated gait and sought to pass through a narrow (80-cm-wide) passage a few metres later. This was followed by a full $\left(360^{\circ}\right)$ turn to the right, a full turn to the left, a turn and half $\left(540^{\circ}\right)$ to the right, a turn and half to the left, a full turn to the right as quickly as possible, a full turn to the left as quickly as possible, a turn and half to the right as quickly as possible, a turn and half to the left as quickly as possible and then a "go" while counting backwards in threes (starting from a number between 100 and 200), (Figure 1 and 
Freezing of gait in PD: brain metabolism

the video in the Supplemental data). The trajectories were performed continuously for the 30 minutes between radiotracer injection and PET acquisition.

Please insert Figure 1 about here

\subsection{Data acquisition and analysis}

\subsubsection{FoG evaluation}

We used a stopwatch to measure the cumulative duration of FoG episodes during the 30minute FoG trajectories preceding the PET acquisition (Schaafsma et al., 2003). Each observer tagged the onset of a FoG episode by pressing the stopwatch's button and holding it down until the end of the episode. FoG was considered to be (i) paroxysmal, very small shuffling steps with minimal forward movement (contrasting with the patients' previous steps), (ii) leg trembling in the absence of effective forward motion or (iii) complete akinesia (i.e. no observable motion of the legs) (Schaafsma et al., 2003). The end of each episode of FoG was defined as the time when the patient took an effective step with a relatively normal step length and swing phase (Schaafsma et al., 2003). Data on all subtypes of FoG (start hesitation, trembling in place and FoG when turning, when approaching a narrow gap or when preparing to stop) were pooled. Hence, the percent time with FoG was defined as the ratio of the cumulative duration of FoG episodes to the total test duration (30 minutes). We choose to record the percent time with FoG in order to obtain an objective measure of freezing (Shine et al., 2012); this criterion is more reliable and more accurate than the number of FoG episodes or the mean duration of a FoG episode (Morris et al., 2012).

\subsection{2. $\quad$ PET data}


All participants underwent PET scans at the same centre (the Nuclear Medicine Department at Lille University Hospital, Lille, France). The same acquisition and image reconstruction procedures were used for the resting and gait conditions in all patients.

\subsubsection{PET data acquisition}

Data were acquired on an Advance SL PET/CT system (GE Medical Systems, General Electric Company, Chalfont St. Giles, UK) with a $5 \mathrm{~mm}$ full-width at half-maximum and a $30 \mathrm{~cm}$ transaxial field of view. Participants were instructed to fast before the scans, and the patient's blood glucose level was always checked prior to intravenous injection of between 185 and $198 \mathrm{MBq}$ of $\left[{ }^{18} \mathrm{~F}\right]-\mathrm{FDG}$. Thirty minutes later (i.e. during the radiotracer's stability window from 20 minutes to 90 minutes after injection, reflecting the uptake during the first 20 minutes (Sokoloff et al., 1977)), a low-dose CT scan of the brain was acquired for attenuation correction of the PET data. Emission images were subsequently acquired in three-dimensional mode. The images were reconstructed iteratively using an orderedsubset expectation-maximization algorithm (with two iterations and 21 subsets) in a 256x256 matrix.

\subsubsection{2. $\quad$ PET data processing}

The reconstructed $\left[{ }^{18} \mathrm{~F}\right]-\mathrm{FDG}$ images were first recorded in Digital Imaging and Communications in Medicine format and then transformed into the Neuroimaging Informatics Technology Initiative format for further processing.

Imaging data were processed and statistically analyzed with SPM5 (Wellcome Department of Cognitive Neurology, London, UK) implemented in MATLAB 7 (Mathworks Inc., Sherborn, MA, USA). Reconstructed $\left[{ }^{18} \mathrm{~F}\right]-\mathrm{FDG}$ brain PET images were spatially normalized against the Montreal Neurological Institute (MNI) template (McGill University, Montreal, Canada) using an affine transformation (with 12 parameters for rigid transformations) (Friston, 1995). To increase the signal-to-noise ratio, the images were 
smoothed by convolution with an isotropic Gaussian kernel (12 $\mathrm{mm}$ full-width at halfmaximum). An overall normalization was applied by including each subject's mean global activity as a covariate of no interest. Thus, our patient-by-patient analysis focused on individual differences in regional brain activity as a proportion of overall brain activity.

\subsubsection{PET data analysis}

First, the Talairach applet (Lancaster et al., 1997, 2000) (Research Imaging Institute of the University of Texas Health Science Center San Antonio (UTHSCSA) was used to determine the location of the nearest grey matter for each significant peak (from the wholebrain analysis). Since the applet uses Talairach space, the coordinates were first translated from MNI space with the MNI-Talairach Coordinate Converter (www.bioimagesuite.org), as presented in Tables. Next, in order to specifically explore areas of the cortex, brainstem and basal ganglia, we defined a number regions of interest (ROIs): the primary motor cortex, dorsal premotor area, dorsolateral prefrontal cortex, medial prefrontal cortex, posterior parietal cortex, subthalamic nucleus, thalamus, putamen, globus pallidus, caudate nucleus, ventral striatum and MLR, as described by Shine et al. (2013a). The coordinates of each ROI were registered on each PET scan (normalized in MNI space).

\subsection{Statistical analysis}

When considering clinical data, intergroup differences in continuous variables were evaluated with an unpaired Student's $t$ test (for variables with a normal distribution according to the Shapiro-Wilk test) or a Wilcoxon test (for non-normal distributions). A chi-squared test was used for categorical variables. The threshold for statistical significance was set to $p<0.05$. All statistical analyses of clinical data were performed with IBM SPSS for Windows software (version 16.0, IBM, Armonk, NY, USA). 
For functional imaging data, we first performed voxel-wise whole-brain analyses by using the flexible factorial design in SPM5. Clusters of at least 30 contiguous voxels with a threshold two-tailed $\mathrm{p}$ value $<0.005$ were considered to be statistically significant. We included each of the following variables in turn: subject, group (FoG vs. non-FoG) and condition (resting vs. gait). We tested for a main effect of condition (resting vs. gait), a main effect of group (FoG vs. non-FoG) and a group $x$ condition interaction. Both increases and decreases in glucose metabolism were analyzed. Post-hoc analyses were based on the "compare-populations one scan/subject" routine. For each voxel, a simple, fixed-effect $\mathrm{T}$ test was used to compare the two groups or pairs of conditions. For analyses of ROIs, spherical volumes with a $5 \mathrm{~mm}$ radius around the peak coordinates of each ROI were defined and a t test was used to compare the two groups $\left(\mathrm{p}_{\text {voxel }}\right.$ uncorrected $=0.005$ ). Lastly, we explored correlations between brain metabolism during gait and the percent time with FoG in the FoG group with a simple regression analysis.

\section{RESULTS}

\subsection{Characteristics of the study population}

The FoG trajectories performed before the "gait" image acquisition were effective in eliciting FoG episodes. All patients in the FoG group presented FoG episodes, and the mean $( \pm$ SD) total duration of FoG per patient was $12( \pm 7)$ minutes (i.e. $39 \%( \pm 23 \%)$ of the 30-minute FoG trajectory; range: 13-77\%). No FoG episodes were recorded in the nonFoG group. Gait was more impaired in the FoG group, as shown in Table 1. Due to the FoG itself and the gait impairment between FoG episodes, the number of FoG trajectories completed was obviously lower and more variable in the FoG group. The time needed to complete one FoG trajectory was comprised between 2 and 13 min in the FoG group, compared with 1.5 to $1.8 \mathrm{~min}$ in the non-FoG group. Even though the FoG trajectory 


\section{Freezing of gait in PD: brain metabolism}

\section{ACCEPTED MANUSCRIPT}

(which was the same for all patients) comprised several triggers, most of the FoG episodes in the FoG group were triggered by turning.

\section{Please insert Table 1 about here}

Intergroup comparisons did not reveal any FoG vs. non-FoG differences in demographic and cognitive data in general or the patients' age, gender, Mini Mental State Examination scores and Mattis Dementia Rating Scale score in particular. There was a non-significant trend toward higher off-drug UPDRS III scores $(\mathrm{p}=0.124)$ and a longer time since disease onset in the FoG group, when compared with the non-FoG group $(\mathrm{p}=0.007)$. The two groups differed regarding the gait subscore in off drug (UPDRS III) and freezing subscore (UPDRS II). FoG scores were correlated with motor axial symptoms, as has been observed previously (Giladi et al., 2000, 2001) (Table 2). However, FoG scores (concerning off drug FoG) were not correlated with postural stability nor gait item in on drug (UPDRS II), but with gait item in off drug (UPDRS III).

Please insert Table 2 about here

3.2. Brain metabolism: $\left[{ }^{18} \mathrm{~F}\right]-\mathrm{FDG}$ PET at rest and after the FoG trajectory (Table 3)

Please insert Table 3 about here

3.2.1. Brain glucose metabolism at rest in patients in the FoG and non-FoG groups

At rest, there was no difference in brain glucose metabolism between the FoG and nonFoG groups.

3.2.2. Brain glucose metabolism after gait (vs. rest) in patients (Figure 2)

3.2.2.1. The non-FoG group 


\section{Freezing of gait in PD: brain metabolism}

\section{ACCEPTED MANUSCRIPT}

In a whole-brain analysis, patients in the non-FoG group displayed post-gait hypermetabolism (vs. rest) in the secondary visual cortex (Brodmann area (BA)18), associative visual cortex (BA19)), premotor cortex (BA6), dorsolateral prefrontal cortex (BA9), somatosensory associative cortex (BA7), cerebellum (culmen), temporoparietal junction (including the superior and middle temporal gyri (BA22 and BA21), supramarginal gyrus (BA40), anterior transverse temporal area (BA41)) and posterior cingulate cortex $(\mathrm{BA} 31)(\mathrm{p}<0.005)$. All the clusters withstood correction for the false discovery rate $(<0.05)$ (Table 3$)$.

\section{Please insert Figure 2 about here}

The results of the ROI analysis are presented in Table 4. In the basal ganglia, activation after gait (compared with rest) was only significant for the right thalamus and the subthalamic nuclei. There were no differences for the putamen or the caudate nucleus.

\section{Please insert Table 4 about here}

\subsubsection{The FoG group}

In a whole-brain analysis, the patients in the FoG group showed post-gait hypermetabolism (vs. rest) in the secondary visual cortex (BA18), premotor cortex (BA6), dorsolateral and anterior prefrontal cortices (BA9 and BA10), primary somatosensory cortex (BA3), cerebellum (the culmen, tonsil, and semi-lunar lobule), basal ganglia, temporoparietal junction (BA40, BA41 and the insula (BA13)) and cingulate cortex (BA30) $(\mathrm{p}<0.005)$. All the clusters withstood correction for the false discovery rate $(<0.005$ for the first eight clusters and $<0.05$ for the following clusters) (Table 3 ).

The results of the ROI analysis are presented in Table 4. There was overall activation after gait (vs. rest) in the basal ganglia (including the thalamus, subthalamic nucleus and putamen). In contrast, the globus pallidus and the MLR displayed significant 
Freezing of gait in PD: brain metabolism

hypometabolism after gait. The FoG group did not activate the medial prefrontal region after gait; in fact, there was a non-significant trend towards deactivation.

\subsubsection{Comparison of brain metabolism after gait in FoG and non-FoG patients (Figure 3)}

When comparing the two groups, the non-FoG group showed greater activation of the temporopolar area (BA38), orbitofrontal area (BA11) and associative premotor cortex (BA8) $(\mathrm{p}<0.005)$. Conversely, the FoG group showed greater activation around the intraparietal sulcus in the paracentral lobule $(\mathrm{BA} 5)(\mathrm{p}<0.005)$.

In the ROI analysis, the FoG group showed hypermetabolism (relative to the non-FoG group) in the globus pallidus and left posterior parietal cortex and hypometabolism in the left dorsolateral prefrontal cortex.

\section{Please insert Figure 3 about here}

The results were generally similar when disease duration and gender were added as covariates (Table 5), with greater metabolic activity after gait in the premotor area, frontal eye fields (FEFs) and somatosensory association cortex in the non-FoG group and in the claustrum, cerebellum and primary visual cortex in the FoG group. Lastly, we observed activation of the temporopolar area and pars orbitalis in the FoG group when disease duration and gender were added as covariates. However, none of the clusters withstood correction for the false discovery rate. Only the 875 -voxel cluster located in the right supplemental motor area (BA 6 , around $(37 ; 1 ; 57)$ ) tended to withstand correction for the false discovery rate $(0.254)$ and the family wise error $(0.121)$.

Please insert Table 5 about here 


\subsection{Clinical and metabolic correlations (Table 6)}

In the FoG group, the percent time with FoG was positively correlated with the activity of the cerebellum, paracentral lobule (BA5) and the right FEF (BA8). Conversely, the percent time with FoG was negatively correlated mainly with the activity in the orbitofrontal area, premotor cortex, the left SMA and temporal lobe. For the study population as a whole, we also found a positive correlation between the UPDRS III gait score and the activity of the cerebellum, FEFs (BA8) and basal ganglia after gait. In contrast, it was negatively correlated with the activity mainly in the orbitofrontal area, premotor cortex, SMAs and temporal lobe (Figure 4).

\section{Please insert Figure 4 and Table 6 about here}

\section{DISCUSSION}

This $\left[{ }^{18} \mathrm{~F}\right]$-FDG-PET study is the first to evidence abnormal brain metabolic activation after actual gait in PD patients with FoG. The frontal and parietal cortical FDG uptake seen in non-FoG PD patients differed from that seen in patients with FoG; the latter displayed significant deregulation of the premotor area (notably the premotor cortex and SMA, which are involved in both the indirect cortical locomotor pathway (la Fougère et al., 2010) and attentional mechanisms) and the output of the basal ganglia (namely the globus pallidus-MLR complex). We will first discuss the frontoparietal network and its implication concerning locomotor adaptation according to the environment, then implication of other motor networks (basal ganglia and cerebellar loops) and their involvement in this type of gait.

As previously described for human locomotor control (Jahn et al., 2008a; la Fougère et al., 2010), the classical components of the supraspinal locomotor network are indeed present in our PD patients. In fact, the brain areas involved in PD gait can be grouped together, as 


\section{Freezing of gait in PD: brain metabolism}

\section{ACCEPTED MANUSCRIPT}

follows: (i) the basal ganglia (involved in motor program selection, (Grillner et al., 2008)), (ii) the cerebellum (involved in rhythm generation, (Grillner, 1985)) (iii) the sensory cortices (for external inputs in general, with a key role in proprioception for motor control in PD (Almeida et al., 2005; Jacobs and Horak, 2006; Schrader et al., 2008; Konczak et al., 2009; Tan et al., 2011)), (iv) the temporoparietal junction (for the multimodal sensory integration of external cues and updating of environmental information via a bottom-up mechanism, (Corbetta and Shulman, 2002; Yang and Mayer, 2014)) and (v) the prefrontal cortex (via a top-down mechanism that regulates pertinent sensory inputs and adapts the motor gait program accordingly (Corbetta and Shulman, 2002; Taylor et al., 2007; Cools et al., 2010)).

Our results are generally consistent with published MRI perfusion data, i.e. in freezers patients an (i) hyperactivation within the paracentral lobule and basal ganglia and (ii) cerebellar dysfunction or (iii) corticosubcortical decoupling, (Shine et al., 2013a; Vercruysse et al., 2014b; Maillet et al., 2015). The differences with regard to the literature data are discussed below.

\subsection{Balance inside the frontoparietal network after gait}

First, the results of the whole-brain analysis revealed a premotor vs. parietal contrast, with greater premotor activation in the non-FoG PD group and greater parietal activation in the FoG group. The parietal cortex provides the input for the parietal-premotor and frontoparietal networks (Battaglia-Mayer et al., 2003). In fact, the frontoparietal network may be one of the major functional substrates for modulated gait in PD because it is responsible for integrating external and internal modalities and comparing them with the goal (gait, in this case) (Battaglia-Mayer et al., 2003).

\subsubsection{Role of attention}


Freezing of gait in PD: brain metabolism

During gait, the motor program is continuously updated by incoming information. The frontotemporal networks ensure that goal-relevant information receives priority; for example, they will reorient attention if a visual trigger requiring adaptation of the motor program occurs. During modulated gait, the patient has to focus attention on obstacles on his/her path (e.g. when turning in a corridor or upon reaching some stairs) and then adapt his/her trajectory and cadence. However, the patient also has to filter out stimuli that are not behaviourally relevant (e.g. markings on the ground such as threshold strips, or unrelated vocal sounds). Lastly, the most important aspect is the assignment of an appropriate, patient-scaled behavioural response to each stimulus (rather than an exaggerated response in a confined space, for example).

The attentional system includes two networks: the dorsal one (including regions of the intraparietal sulcus, superior parietal cortex, FEF, premotor cortex (SMA), dorsolateral prefrontal cortex) tends to be active during focused, goal-directed attention to a particular target (here gait), whereas the ventral one (including the temporoparietal junction, inferior frontal gyrus, lateral and inferior frontal/prefrontal cortex and anterior insula) is associated with redirecting attention toward stimuli that are relevant to the immediate goal (Corbetta et al., 2008; Asplund et al., 2010; Frank and Sabatinelli, 2012), called stimulus-driven attention. The balance between dorsal and ventral subdivisions of the frontoparietal network requires determining the locus of attention, disengaging and reorienting attention as necessary (Corbetta and Shulman, 2002), especially by determining which stimuli are relevant or not according the task.

Normally, as task difficulty increases, activity suppression in the ventral network correlates positively with task performance, an effect thought to reflect the gating of irrelevant cues (Frank and Sabatinelli, 2012). It would be expected that during this high-asking attention task with several FoG trajectories, the stimuli integration level would decrease. Indeed, in 
the non-freezers patients, this task majority involves the dorsal network, including activation of the FEF, premotor cortex (SMA) and dorsolateral prefrontal cortex. In contrast, in the FoG group, there was a poor frontal activation in FoG, accordingly with less inhibition or gating from frontal to parietal structures (Konishi et al., 1999; Downar et al., 2000, 2001) and then higher activation of the ventral network. Supporting the hypothesis of the impairment of interaction between dorsal and ventral ways in freezers patients, our study showed that the FoG group had less activation of the dorsal pathway than the non-FoG group after gait, mainly in SMA and FEF (Tables 3-5). Moreover, gait scores were positively correlated with the ventral way's activation (inferior frontal gyrus) (Table 6 and Figure 4).

The cingulate cortex was activated by FoG trajectories in both the FoG and non-FoG groups, whereas the temporopolar and orbitofrontal areas were activated in non-FoG patients (relative to FoG patients). Concerning the ventral frontal cortex (ventromedial -BA 10, 11 and 47- and ventrolateral-BA 44, 45 and 47-), its activation after gait was generally positively correlated with the gait score and negatively with the time of freezing. Considering its role in decision making and in stimulus-outcome associations, it could be involved in facilitating changes of behaviour in case of unexpected outcomes (Murray et al., 2007; O’Doherty, 2007). This reversal action, reflecting flexibility, guides selection of the most advantageous choices considering potential positive and negative consequences. Then the ventral frontal cortex could act to signal the task transition and readjust between the dorsal and ventral attentional networks, to priorize goal or stimulus according to the situation (Shulman et al., 2002; Corbetta et al., 2008). It also could be involved in the transitions between task boundaries as complex gait should not be considered as a continuous activity but as a series of event with interruptions and terminations requiring updating (Bouret and Sara, 2005; Zacks and Swallow, 2007; Corbetta et al., 2008). 
Freezing of gait in PD: brain metabolism

It is also important to note that when disease duration and gender were added as covariates, the hypometabolism of temporopolar area after gait decreased in the FoG group - suggesting that the hypometabolism of this area observed in the FoG group is more related to more advanced disease.

\subsubsection{Sensory integration: the parietal pole}

The greater activation of parietal areas in patients with FoG may reflect an increased need to rely on external cues because internal integration is impaired (Hallett, 2008). It may also reflect difficulty in resisting external interference (Naismith et al., 2010; Vandenbossche et al., 2011). Increased brain activation in the FoG group appears to reflect increased processing of sensory inputs rather than increase in inputs per se (which are identical for the two groups). Indeed, if proprioceptive afferences intensity are similar between groups during the FoG-trajectories, the level of deregulation could be the cortical integration of body weight load (Mensink et al., 2014) or proprioception (Tan et al., 2011). Exaggerated processing of sensory inputs might explain the "transient disruptions of locomotor circuitry leading to a motor block" (Nutt et al., 2011) when the sensory integration overloads the locomotor network. Usually, the sensitivity to sensory changes sensitivity is controlled by the task-relevance with insensitivity to task-irrelevant perceptual salient stimuli (de Fockert et al., 2004; Kincade et al., 2005). In case of automatic gait for example, the vestibular and somatosensory cortex showed deactivation, which thus prevents adverse interactions with the spinal pattern and sensory signals (Jahn et al., 2004). This multisensory inhibition, operating during unhindered locomotion, seems impaired in freezers patients. Freezers could display disorders in the process of categorizing stimuli, according to task-relevance or not, showing poor goal-directed and abnormal stimulus-driven activation. FoG could 
then be related to an impairment in discriminating what is task (gait) relevant and consider as relevant all distracters.

\subsubsection{Premotor differences between non-FoG and FoG groups after gait.}

In both the whole-brain analysis and the ROI analysis, the premotor cortex and SMA were less activated in the FoG group than in the non-FoG group after gait. This finding is in line with literature reports (Snijders et al., 2011; Herman et al., 2013; Shine et al., 2013a). Differences in this region might be due to several different mechanisms - especially those affecting attentional networks and those involved in externally guided (visually guided) movements (Corbetta and Shulman, 2002). In line with our present observations, preferential use of the premotor area in PD has also been described for alternating finger movements (Samuel et al., 1997) and "paradoxical gait" (Hanakawa et al., 1999a), in which visual stimuli improved the PD patients' gait parameters. The FEF that adjusts the visuospatial exploration during gait (by guiding the eye and head movements) might also have a key role here (Pierrot-Deseilligny et al., 2003; Koyama et al., 2004; Brown et al., 2008), as suggested by the correlation between the percent time with FoG and FEF activation. The SMA is classically considered as comprising an anterior region (the preSMA, involved in the early stages of motor processing such as motor selection and preparation) and a posterior region (the SMA proper, involved in later stages such as initiation and execution of the motor program) (Matsuzaka et al., 1992; Passingham, 1997; Lee et al., 1999). The difference between FoG and non-FoG patients highlighted here (Figure 2) mainly concerns the posterior SMA; this may reflect that freezers have greater difficulties in initiation and execution than in motor selection. This is suggested (for example) by endless repetition of the motor program during trembling in place - a phenomenon frequently observed during gait initiation (Jacobs et al., 2009b). However, the 
coupling between preparation and execution is also included in pathophysiological hypotheses (Jacobs et al., 2009a; Nutt et al., 2011), making it difficult to distinguish between these two components in an analysis of FoG. Lastly, the respective involvements of the preSMA and/or SMA proper might vary as a function of the subtype of freezing (freezing during initiation vs. freezing when turning, for example). One can hypothesize that (i) the preSMA is more involved in gait initiation failure and (ii) the SMA proper is more involved in freezing during movement execution (which was more frequent here). However, our paradigm was unable to distinguish between the metabolic patterns respectively associated with these two subtypes of FoG - although it was noteworthy that freezing in our FoG group occurred mainly when turning.

\subsubsection{Pathophysiological hypotheses}

Deregulation of the frontoparietal network in freezers might explain the dual nature of external cueing in FoG. Under ecological conditions, external cues (such as dual tasks) are often disruptive and trigger FoG - probably by overloading the basal ganglia (according to Shine et al.'s model (2011a)) and making gait less automatic. In contrast, external cues can also improve gait parameters (i.e. by increasing step length and lowering step cadence) (Azulay et al., 2006) and might thus decrease FoG (at least temporarily, until the repeated use of the strategy wears off). Hence, external cues (whether auditory or visual) may also help the patient to overcome FoG episodes, when the cues' function is to normalize gait parameters (Nutt et al., 2011). One can hypothesize that the premotor area's role is particularly enhanced when visuomotor modulation is intense. Indeed, when the cues are similar to the standardized gait program, visuomotor coordination is enough to produce relatively normal gait in the FoG group (due to the maintenance of parietal inputs). In contrast, cues that are unrelated to the internal motor program (i.e. external cues that distract attention from redefined motor patterns) will oblige the premotor area to detect 


\section{Freezing of gait in PD: brain metabolism}

\section{ACCEPTED MANUSCRIPT}

motor errors (i.e. mismatch between the executed motor program and the environment, in terms of speed or direction) and correct them by adapting the motor program via the modulation of the downstream structures. We suggest that this latter mechanism is inefficient in the FoG group.

Furthermore, it is important to note that the brain regions in which metabolic activity was correlated with FoG were largely those correlated with gait impairments in general (Table 6). More severe impairment was related to greater metabolic activity in the FEFs, cerebellum and basal ganglia activity and lower metabolic activity in the premotor and orbitofrontal areas. This finding suggests that there is a continuum between gait disorders and freezing, which might be related to an imbalance between compensatory frontal mechanisms and more basic locomotor networks.

Correlations for time spent with FoG were less unicist (with a positive correlation with FEF and a negative correlation with inferior frontal gyrus, Table 6). Maybe this difference could be explained by the smaller effective (only FoG patients were included here) or could reflect different mechanisms, both impairment and compensation attempt when gait without FoG restart (restart of the dorsal way).

\subsection{The ROI analysis: FoG vs. non-FoG differences in activation of the basal ganglia activation.}

In our study, the basal ganglia (namely the putamen) were activated after gait (compared with rest) in the FoG group but not in the non-FoG group. The FoG group showed greater activation of the globus pallidus and thalamus, which may lead to deregulation of the MLR (Lewis and Barker, 2009; Shine et al., 2011a). 
Freezing of gait in PD: brain metabolism

Use of the basal ganglia's thalamocortical circuits may manifest itself via "jamming motor execution" in FoG (as seen for trembling in place (Schaafsma et al., 2003)) or by a total arrest in motor execution (as in start hesitation) (Schaafsma et al., 2003).

After gait with FoG, our results evidenced (i) greater activation of the putamen and thalamus (ii) and significant deactivation of the basal ganglia's outputs (the globus pallidus and MLR). The MLR is functionally and anatomically impaired in PD, and the impairment increases with disease progression (Karachi et al., 2010). Functional imaging studies with various paradigms have shown that the MLR is involved in FoG (Snijders et al., 2011; Shine et al., 2013a; Maillet et al., 2015). Although we did not observe intergroup differences in MLR activation in the whole-brain analysis, the ROI analysis showed that this area was significantly deactivated after complex gait in the FoG group. The lack of a significant difference in the present study and the trend to deactivation (in contrast to the study by Snijders et al. (2011) and Maillet et al. (2015)) may be due to methodological differences. Activation of the MLR may be more related to mental imagery of gait initiation, which requires inhibition of the engaged motor program (Jahn et al., 2008b) because motor execution was imagined rather than performed. Furthermore, our study focused on the underlying locomotor pattern associated with FoG and not solely on the narrow time window within which FoG occurs (Shine et al., 2013a). Indeed, gait initiation episodes are much less frequent during actual gait trajectories than during mental imagery paradigms (every 4 to 12 seconds for 25 minutes, for example, in the study by Snijders et al., 2011). It is noteworthy that prefrontal cortex hypoactivation and the absence of MLR hyperactivation were recently described in patients with progressive supranuclear palsy (of which FoG is a cardinal feature) during a modulated gait paradigm (as used in the present study) (Zwergal et al., 2013). 
As also reported by Shine et al. (2013a), we observed greater cortical activation in patients with FoG after gait (relative to rest, Table 4). This activation involved not only the primary motor cortex (as in non-FoG patients) but also the premotor area and the posterior parietal cortex. These observations are also suggestive of cortico-subcortical decoupling. When comparing gait with rest within each group, cortical activation was more widespread (i.e. spatially extended) in patients with FoG (although no intergroup differences were noted for the resting condition). This probably corresponds to an attempt by patients with FoG to (i) compensate for impairment of the basal ganglia and (ii) use the external environment to adapt the gait parameters. However, when comparing the two groups after activation by real gait trajectories (i.e. the intergroup contrast), overall activation of the premotor area was less intense in patients with FoG than in patients without FoG. Indeed, cortical activation in patients with FoG was greater in the parietal part of the frontoparietal network (which handles sensory inputs). In contrast, the frontal pole (which handles motor outputs) is poorly activated and is unable to directly shunt the basal ganglia. These observations may explain why our metabolic results (with glucose uptake averaged over 30 minutes of gait) highlighted relatively low activation in the premotor area in patients with FoG, whereas studies exploring perfusion during mental imagery of gait (with the equivalent of FoG-like episodes) reported hyperactivation of the premotor area (Maillet et al., 2015). The premotor activation during FoG or FoG-like episodes may also exist in freezers but is less intense than that observed in non-freezers. These results are consistent with a hypothesis in which the external loop has a compensatory role (Hanakawa et al., 1999a, 1999b; la Fougère et al., 2010) but is not sufficiently effective in PD patients with FoG. Our present results highlighted (i) the low overall activation of the premotor area after gait in PD patients with FoG but (ii) a positive correlation between the percent time with FoG and the metabolism of the FEFs (as similarly shown during upper limb motor blocks by 


\section{Freezing of gait in PD: brain metabolism}

\section{ACCEPTED MANUSCRIPT}

Vercruysse et al. (2014a)). These observations suggest that PD patients with FoG attempt to use this parietofrontal network but that the latter does not effectively adapt the motor program.

\subsection{Is the cerebellar network also involved in gait with freezing?}

Intergroup differences in the frontal and parietal regions might also reflect the involvement of neocerebellar circuits via frontopontine and parietopontine fibres. Indeed, metabolism in the paracentral lobule, superior frontal gyrus and neocerebellar lobes was correlated with the percent time with FoG during the gait task preceding the PET acquisition. These areas belong to the neocerebellar network, which processes sensory information monitors and optimizes movements by using sensory feedback (Jueptner and Weiller, 1998) (via visuomotor coordination, for instance (van der Hoorn et al., 2014)). Interaction with the basal ganglia's thalamocortical loops is required to coordinate the afferent sensory component (the neocerebellar loop) and the efferent motor component (with selection of appropriate muscles and movements). Future research must determine which motor networks are involved in complex gait and whether (as seems likely) communication between them is impaired in patients with FoG.

Even after gender and disease duration were added as covariates, we again observed hyperactivation of the cerebellum, primary visual cortex and claustrum in freezers after gait (reflecting the preferential use of basic rhythmic loops (Tanné-Gariépy et al., 2002; Smith et al., 2012). 


\subsection{Putative brain lateralization in FoG}

Our findings are somewhat limited by the question of laterality: in freezers, left-side premotor hypometabolism was observed when studying the effect of group, whereas rightside premotor hypometabolism was highlighted when studying the effect of gait condition. Bilateral involvement is probable but was not unambiguously demonstrated here - perhaps due to the small sample size. Literature studies of paradoxical gait in PD have shown hyperperfusion of the right premotor cortex (Hanakawa et al., 1999), whereas a mental imagery task revealed hyperperfusion of the left supplementary motor cortex in nonfreezers (relative to freezers) (Snijders et al., 2011). The left premotor cortex is sometimes considered to have a preferential role in goal-directed movement (Schluter et al., 1998, 2001; Rushworth et al., 2003), although this may have been due to the preferential use of right-hand motor paradigms. In contrast, Bartels and Leenders (2008) suggested that FoG is caused by neuronal circuitry dysfunctions in the right parietal-lateral premotor area (Crémers et al., 2012; Fling et al., 2013; Maillet et al., 2015; Peterson et al., 2014a). In freezers, hypometabolism has been detected in the left premotor area and in the right parietal cortex (Bartels et al., 2006), showing that the both sides of the cortex are affected (albeit in different areas). In fact, there is no clear evidence of laterality of the premotor cortex in action selection (whether in response to visuospatial signals or not) (Wise et al., 1997). For bilateral movements, action selection is probably underpinned by a bilateral network (Horenstein et al., 2009) within which the left and right premotor cortices interact (O'Shea et al., 2007). The laterality of FoG merits further investigation.

\subsection{Study limitations}

The present study had several limitations. Firstly, the sample size was small for such a complex disease phenomenon; the lack of statistical power explains why the effect of 
Freezing of gait in PD: brain metabolism

group was not corrected for multiple comparisons. Secondly, and even though the FoG and non-FoG groups did not differ significantly in terms of age and motor scores, the disease duration was longer in the FoG group (as is generally observed in this type of patient (Perez-Lloret et al., 2014)). This disparity might explain in part the regional metabolic differences between the groups.

Thirdly, our study was unable to discriminate between the paroxysmal mechanisms corresponding to the various components associated with FoG (such as gait hypokinesia, sequence effects and sudden motor blocks) and the different subtypes of FoG. The injection of perfusion radiotracers (such as ${ }^{99 \mathrm{~m}} \mathrm{Tc}$-bicisate) at the time at which each specific subtype of FoG occurs (e.g. FoG during turns) might enable characterization of the corresponding brain perfusion patterns. Lastly, axial symptoms are generally more frequent in freezers (Giladi et al., 2001) - even though the axial subscore was similar in our FoG and non-FoG groups- and may be related to the same pathophysiological mechanisms as FoG itself (Park et al., 2014; Veryoort et al., 2013). Axial symptoms (such as postural stability) are involved in motor control processes related to balance during locomotion. Indeed, axial symptoms form part of the spectrum of gait disturbances encompassing paroxysmal FoG (Heremans et al., 2013), slow execution speed and low step length. Hence, axial symptoms may also account for intergroup differences in brain metabolism after gait (Karachi et al., 2010). These confounding variables must be systematically monitored in future studies.

In PD patients performing arm movements, high movement velocity was associated with hyperperfusion of the premotor and parietal areas (Turner et al., 2003), whereas low movement velocity was associated with hypoperfusion of the left dorsolateral prefrontal and premotor cortices (Carbon et al., 2007). In patients with progressive supranuclear palsy, post-gait differences in brain metabolism (vs. healthy controls) were still significant 


\section{Freezing of gait in PD: brain metabolism}

\section{ACCEPTED MANUSCRIPT}

after adjustment for gait velocity (Zwergal et al., 2013). Taken as a whole, these data suggest that the premotor hypometabolism observed in freezers may be partly due to a more general gait impairment (including a lower gait speed outside FoG episodes).

\subsection{Conclusion}

The present study is the first to demonstrate a characteristic, FoG-associated cortical pattern of metabolic activation in a paradigm including real gait performed by PD patients. In the FoG group, we notably observed (i) hypoactivation of the frontal premotor cortex, (ii) hyperactivation of the parietal cortices and (iii) deregulation of the basal ganglia output (globus pallidus and MLR). Further multimodal imaging studies may help to elucidate the mechanisms underlying FoG in PD patients and prompt the development of techniques for modulating the affected brain networks (such as the frontoparietal and/or neocerebellar networks) involved in visually guided movements (like complex gait) in PD. In parkinsonian patients, the parieto-premotor network could be considered as a compensatory network, that could be overloaded in freezers in different situations such as when they had to reduce their step length (looking at visual cues consisted in white strips placed on the floor) leading to FoG (Iansek et al., 2006; Chee et al., 2009). This task could be further investigated specifically by brain imaging techniques.

\section{ACKNOWLEDGEMENTS}

We thank David Fraser (Biotech Communication) for editorial assistance.

\section{REFERENCES}


Almeida QJ, Frank JS, Roy EA, Jenkins ME, Spaulding S, Patla AE, Jog MS (2005), An evaluation of sensorimotor integration during locomotion toward a target in Parkinson's disease. Neuroscience 134:283-293.

American Psychiatric Association. (1994) Diagnostic and statistical manual of mental disorders, 4th ed. Washington, DC: American Psychiatry Association.

Asplund CL, Todd JJ, Snyder AP, Marois R (2010), A central role for the lateral prefrontal cortex in goal-directed and stimulus-driven attention. Nat Neurosci 13:507-512.

Azulay J-P, Mesure S, Blin O (2006), Influence of visual cues on gait in Parkinson's disease: contribution to attention or sensory dependence? J Neurol Sci 248:192-195.

Bartels AL, de Jong BM, Giladi N, Schaafsma JD, Maguire RP, Veenma L, Pruim J, Balash Y, Youdim MBH, Leenders KL (2006), Striatal dopa and glucose metabolism in PD patients with freezing of gait. Mov Disord 21:1326-1332.

Bartels AL, Leenders KL (2008), Brain imaging in patients with freezing of gait. Mov Disord 23 Suppl 2:S461-S467.

Battaglia-Mayer A, Caminiti R, Lacquaniti F, Zago M (2003), Multiple levels of representation of reaching in the parieto-frontal network. Cereb Cortex 13:1009-1022.

Bohnen NI, Koeppe RA, Minoshima S, Giordani B, Albin RL, Frey KA, Kuhl DE (2011), Cerebral glucose metabolic features of Parkinson disease and incident dementia: longitudinal study. J Nucl Med 52:848-855.

Bouret S, Sara SJ (2005), Network reset: a simplified overarching theory of locus coeruleus noradrenaline function. Trends Neurosci 28:574-582.

Brown JW, Hanes DP, Schall JD, Stuphorn V (2008), Relation of frontal eye field activity to saccade initiation during a countermanding task. Exp Brain Res 190:135-151. 


\section{Freezing of gait in PD: brain metabolism}

\section{ACCEPTED MANUSCRIPT}

Carbon M, Felice Ghilardi M, Dhawan V, Eidelberg D (2007), Correlates of movement initiation and velocity in Parkinson's disease: A longitudinal PET study. Neuroimage $34: 361-370$.

Chee R, Murphy A, Danoudis M, Georgiou-Karistianis N, Iansek R (2009), Gait freezing in Parkinson's disease and the stride length sequence effect interaction. Brain 132:21512160.

Cohen RG, Chao A, Nutt JG, Horak FB (2011), Freezing of gait is associated with a mismatch between motor imagery and motor execution in narrow doorways, not with failure to judge doorway passability. Neuropsychologia 49:3981-3988.

Cools R, Rogers R, Barker RA, Robbins TW (2010), Top-down attentional control in Parkinson's disease: salient considerations. J Cogn Neurosci 22:848-859.

Corbetta M, Patel G, Shulman GL (2008), The reorienting system of the human brain: from environment to theory of mind. Neuron 58:306-324.

Corbetta M, Shulman GL (2002), Control of goal-directed and stimulus-driven attention in the brain. Nat Rev Neurosci 3:201-215.

Crémers J, Dessoullières A, Garraux G (2012), Hemispheric specialization during mental imagery of brisk walking. Hum Brain Mapp 33:873-882.

de Fockert J, Rees G, Frith C, Lavie N (2004), Neural correlates of attentional capture in visual search. J Cogn Neurosci 16:751-759.

Dietz V, Müller R, Colombo G (2002), Locomotor activity in spinal man: significance of afferent input from joint and load receptors. Brain 125:2626-2634.

Downar J, Crawley AP, Mikulis DJ, Davis KD (2000), A multimodal cortical network for the detection of changes in the sensory environment. Nat Neurosci 3:277-283. 
Downar J, Crawley AP, Mikulis DJ, Davis KD (2001), The effect of task relevance on the cortical response to changes in visual and auditory stimuli: an event-related fMRI study. Neuroimage 14:1256-1267.

Emre M et al. (2007), Clinical diagnostic criteria for dementia associated with Parkinson's disease. Mov Disord 22:1689-1707.

Espay AJ, Fasano A, van Nuenen BFL, Payne MM, Snijders AH, Bloem BR (2012), "On” state freezing of gait in Parkinson disease: a paradoxical levodopa-induced complication. Neurology 78:454-457.

Fling BW, Cohen RG, Mancini M, Carpenter SD, Fair DA, Nutt JG, Horak FB (2014), Functional Reorganization of the Locomotor Network in Parkinson Patients with Freezing of Gait. PLoS ONE 9:e100291.

Fling BW, Cohen RG, Mancini M, Nutt JG, Fair DA, Horak FB (2013), Asymmetric pedunculopontine network connectivity in parkinsonian patients with freezing of gait. Brain 136:2405-2418.

Folstein MF, Folstein SE, McHugh PR (1975), "Mini-mental state". A practical method for grading the cognitive state of patients for the clinician. J Psychiatr Res 12:189-198.

Frank DW, Sabatinelli D (2012), Stimulus-driven reorienting in the ventral frontoparietal attention network: the role of emotional content. Front Hum Neurosci 6:116.

Friston KJ (1995), Commentary and opinion: II. Statistical parametric mapping: ontology and current issues. J Cereb Blood Flow Metab 15:361-370.

Gibb WR (1988), Accuracy in the clinical diagnosis of parkinsonian syndromes. Postgrad Med J 64:345-351.

Giladi N, McDermott MP, Fahn S, Przedborski S, Jankovic J, Stern M, Tanner C (2001), Freezing of gait in PD: prospective assessment in the DATATOP cohort. Neurology $56: 1712-1721$. 
Giladi N, Tal J, Azulay T, Rascol O, Brooks DJ, Melamed E, Oertel W, Poewe WH, Stocchi F, Tolosa E (2009), Validation of the freezing of gait questionnaire in patients with Parkinson's disease. Mov Disord 24:655-661.

Giladi, Shabtai, Simon, Biran, Tal, Korczyn (2000), Construction of freezing of gait questionnaire for patients with Parkinsonism. Parkinsonism Relat Disord 6:165-170.

Green RC, Woodard JL, Green J (1995), Validity of the Mattis Dementia Rating Scale for detection of cognitive impairment in the elderly. J Neuropsychiatry Clin Neurosci 7:357360.

Grillner S (1985), Neurobiological bases of rhythmic motor acts in vertebrates. Science 228:143-149.

Grillner S, Wallén P, Saitoh K, Kozlov A, Robertson B (2008), Neural bases of goaldirected locomotion in vertebrates--an overview. Brain Res Rev 57:2-12.

Hallett M (2008), The intrinsic and extrinsic aspects of freezing of gait. Mov Disord 23 Suppl 2:S439-S443.

HamiltonM (1959), The assessment of anxiety states by rating. Br J Med Psychol 32:5055.

Hanakawa T, Fukuyama H, Katsumi Y, Honda M, Shibasaki H (1999a), Enhanced lateral premotor activity during paradoxical gait in Parkinson's disease. Ann Neurol 45:329-336. Hanakawa T, Katsumi Y, Fukuyama H, Honda M, Hayashi T, Kimura J, Shibasaki H (1999b), Mechanisms underlying gait disturbance in Parkinson's disease: a single photon emission computed tomography study. Brain 122:1271-1282.

Hausdorff JM, Schaafsma JD, Balash Y, Bartels AL, Gurevich T, Giladi N (2003), Impaired regulation of stride variability in Parkinson's disease subjects with freezing of gait. Exp Brain Res 149:187-194. 


\section{Freezing of gait in PD: brain metabolism}

\section{ACCEPTED MANUSCRIPT}

Heremans E, Nieuwboer A, Vercruysse S (2013), Freezing of gait in Parkinson's disease: where are we now? Curr Neurol Neurosci Rep 13:350.

Herman T, Giladi N, Hausdorff JM (2013), Neuroimaging as a window into gait disturbances and freezing of gait in patients with Parkinson's disease. Curr Neurol Neurosci Rep 13:411.

Herman T, Rosenberg-Katz K, Jacob Y, Giladi N, Hausdorff JM (2014), Gray matter atrophy and freezing of gait in Parkinson's disease: Is the evidence black-on-white? Mov Disord 29:134-139.

Horenstein C, Lowe MJ, Koenig KA, Phillips MD (2009), Comparison of unilateral and bilateral complex finger tapping - related activation in premotor and primary motor cortex. Human Brain Mapping 30:1397-1412.

Iansek R, Huxham F, McGinley J (2006), The sequence effect and gait festination in Parkinson disease: contributors to freezing of gait? Mov Disord 21:1419-1424.

Jacobs JV, Horak FB (2006), Abnormal proprioceptive-motor integration contributes to hypometric postural responses of subjects with Parkinson's disease. Neuroscience 141:999-1009.

Jacobs JV, Lou JS, Kraakevik JA, Horak FB (2009a), The supplementary motor area contributes to the timing of the anticipatory postural adjustment during step initiation in participants with and without Parkinson's disease. Neuroscience 164:877-885.

Jacobs JV, Nutt JG, Carlson-Kuhta P, Stephens M, Horak FB (2009b), Knee trembling during freezing of gait represents multiple anticipatory postural adjustments. Exp Neurol 215:334-341.

Jahn K, Deutschländer A, Stephan T, Kalla R, Hüfner K, Wagner J, Strupp M, Brandt T (2008a), Supraspinal locomotor control in quadrupeds and humans. Prog Brain Res $171: 353-362$. 
Jahn K, Deutschländer A, Stephan T, Kalla R, Wiesmann M, Strupp M, Brandt T (2008b), Imaging human supraspinal locomotor centers in brainstem and cerebellum. Neuroimage 39:786-792.

Jahn K, Deutschländer A, Stephan T, Strupp M, Wiesmann M, Brandt T (2004), Brain activation patterns during imagined stance and locomotion in functional magnetic resonance imaging. Neuroimage 22:1722-1731.

Jueptner M, Weiller C (1998), A review of differences between basal ganglia and cerebellar control of movements as revealed by functional imaging studies. Brain 121:1437-1449.

Karachi C, Grabli D, Bernard FA, Tandé D, Wattiez N, Belaid H, Bardinet E, Prigent A, Nothacker H-P, Hunot S, Hartmann A, Lehéricy S, Hirsch EC, François C (2010), Cholinergic mesencephalic neurons are involved in gait and postural disorders in Parkinson disease. J Clin Invest 120:2745-2754.

Karim HT, Sparto PJ, Aizenstein HJ, Furman JM, Huppert TJ, Erickson KI, Loughlin PJ (2014), Functional MR imaging of a simulated balance task. Brain Res 1555:20-27.

Kincade JM, Abrams RA, Astafiev SV, Shulman GL, Corbetta M (2005), An event-related functional magnetic resonance imaging study of voluntary and stimulus-driven orienting of attention. J Neurosci 25:4593-4604.

Konczak J, Corcos DM, Horak F, Poizner H, Shapiro M, Tuite P, Volkmann J, Maschke M (2009), Proprioception and motor control in Parkinson's disease. J Mot Behav 41:543-552.

Konishi S, Kawazu M, Uchida I, Kikyo H, Asakura I, Miyashita Y (1999), Contribution of working memory to transient activation in human inferior prefrontal cortex during performance of the Wisconsin Card Sorting Test. Cereb Cortex 9:745-753. 
Koyama M, Hasegawa I, Osada T, Adachi Y, Nakahara K, Miyashita Y (2004), Functional magnetic resonance imaging of macaque monkeys performing visually guided saccade tasks: comparison of cortical eye fields with humans. Neuron 41:795-807.

la Fougère C, Zwergal A, Rominger A, Förster S, Fesl G, Dieterich M, Brandt T, Strupp M, Bartenstein P, Jahn K (2010), Real versus imagined locomotion: a [18F]-FDG PETfMRI comparison. Neuroimage 50:1589-1598.

Lancaster JL, Rainey LH, Summerlin JL, Freitas CS, Fox PT, Evans AC, Toga AW, Mazziotta JC (1997), Automated labeling of the human brain: a preliminary report on the development and evaluation of a forward-transform method. Hum Brain Mapp 5:238-242. Lancaster JL, Woldorff MG, Parsons LM, Liotti M, Freitas CS, Rainey L, Kochunov PV, Nickerson D, Mikiten SA, Fox PT (2000), Automated Talairach atlas labels for functional brain mapping. Hum Brain Mapp 10:120-131.

Langston JW, Widner H, Goetz CG, Brooks D, Fahn S, Freeman T, Watts R (1992), Core assessment program for intracerebral transplantations (CAPIT). Mov Disord 7:2-13.

Lee K-M, Chang K-H, Roh J-K (1999), Subregions within the Supplementary Motor Area Activated at Different Stages of Movement Preparation and Execution. NeuroImage 9:117-123.

Lewis SJG, Barker RA (2009), A pathophysiological model of freezing of gait in Parkinson's disease. Parkinsonism \& Related Disorders 15:333-338.

Lucignani G, Schmidt KC, Moresco RM, Striano G, Colombo F, Sokoloff L, Fazio F (1993), Measurement of regional cerebral glucose utilization with fluorine-18-FDG and PET in heterogeneous tissues: theoretical considerations and practical procedure. $\mathrm{J}$ Nucl Med 34:360-369. 
Freezing of gait in PD: brain metabolism

Macht M, Kaussner Y, Möller JC, Stiasny-Kolster K, Eggert KM, Krüger H-P, Ellgring H (2007), Predictors of freezing in Parkinson's disease: a survey of 6,620 patients. Mov Disord 22:953-956.

Maillet A, Pollak P, Debû B (2012), Imaging gait disorders in parkinsonism: a review. J Neurol Neurosurg Psychiatr 83:986-993.

Maillet A, Thobois S, Fraix V, Redouté J, Le Bars D, Lavenne F, Derost P, Durif F, Bloem BR, Krack P, Pollak P, Debû B (2015), Neural substrates of levodopa-responsive gait disorders and freezing in advanced Parkinson's disease: A kinesthetic imagery approach. Hum Brain Mapp 36:959-980

Massion J (1992), Movement, posture and equilibrium: interaction and coordination. Prog Neurobiol 38:35-56.

Matsuzaka Y, Aizawa H, Tanji J (1992), A motor area rostral to the supplementary motor area (presupplementary motor area) in the monkey: neuronal activity during a learned motor task. J Neurophysiol 68:653-662.

Mensink SHG, Nonnekes J, van Bon G, Snijders AH, Duysens J, Weerdesteyn V, Bloem BR, Oude Nijhuis LB (2014), Additional weight load increases freezing of gait episodes in Parkinson's disease; an experimental study. J Neurol 261:999-1008.

Montgomery SA, Asberg M (1979), A new depression scale designed to be sensitive to change. Br J Psychiatry 134:382-389.

Morris TR, Cho C, Dilda V, Shine JM, Naismith SL, Lewis SJG, Moore ST (2012), A comparison of clinical and objective measures of freezing of gait in Parkinson's disease. Parkinsonism Relat Disord 18:572-577.

Murray EA, O'Doherty JP, Schoenbaum G (2007), What we know and do not know about the functions of the orbitofrontal cortex after 20 years of cross-species studies. J Neurosci 27:8166-8169. 
Freezing of gait in PD: brain metabolism

Naismith SL, Shine JM, Lewis SJG (2010), The specific contributions of set-shifting to freezing of gait in Parkinson's disease. Mov Disord 25:1000-1004.

Nieuwboer A, Giladi N (2013), Characterizing freezing of gait in Parkinson's disease: Models of an episodic phenomenon. Mov Disord 28:1509-1519.

Nutt JG, Bloem BR, Giladi N, Hallett M, Horak FB, Nieuwboer A (2011), Freezing of gait: moving forward on a mysterious clinical phenomenon. Lancet Neurol 10:734-744.

O'Doherty JP (2007), Lights, camembert, action! The role of human orbitofrontal cortex in encoding stimuli, rewards, and choices. Ann N Y Acad Sci 1121:254-272.

O'Shea J, Johansen-Berg H, Trief D, Göbel S, Rushworth MFS (2007), Functionally specific reorganization in human premotor cortex. Neuron 54:479-490.

Pappatà S, Santangelo G, Aarsland D, Vicidomini C, Longo K, Bronnick K, Amboni M, Erro R, Vitale C, Caprio MG, Pellecchia MT, Brunetti A, De Michele G, Salvatore M, Barone P (2011), Mild cognitive impairment in drug-naive patients with PD is associated with cerebral hypometabolism. Neurology 77:1357-1362.

Park HK, Kim JS, Im KC, Oh SJ, Kim MJ, Lee J-H, Chung SJ, Lee MC (2009), Functional brain imaging in pure akinesia with gait freezing: [18F] FDG PET and [18F] FP-CIT PET analyses. Moy Disord 24:237-245.

Park HK, Yoo JY, Kwon M, Lee J-H, Lee SJ, Kim SR, Kim MJ, Lee MC, Lee SM, Chung SJ (2014), Gait freezing and speech disturbance in Parkinson's disease. Neurol Sci 35:357-

363.Passingham R (1997) Functional organization of the motor system. In: Human Brain Function (R. S. J. Frackowiak, K. J. Friston, C. D. Frith, R. J. Dolan, and J. C. Mazziotta, Eds.), Academic Press., pp pp. 243-274. San Diego.

Perez-Lloret S, Negre-Pages L, Damier P, Delval A, Derkinderen P, Destée A, Meissner WG, Schelosky L, Tison F, Rascol O (2014), Prevalence, Determinants, and Effect on Quality of Life of Freezing of Gait in Parkinson Disease. JAMA Neurol 71:884-890. 


\section{Freezing of gait in PD: brain metabolism}

\section{ACCEPTED MANUSCRIPT}

Peterson DS, Fling BW, Mancini M, Cohen RG, Nutt JG, Horak FB (2015) Dual-task interference and brain structural connectivity in people with Parkinson's disease who freeze. J Neurol Neurosurg Psychiatry 86:786-792.

Peterson DS, Pickett KA, Duncan R, Perlmutter J, Earhart GM (2014a), Gait-related brain activity in people with Parkinson disease with freezing of gait. PLoS ONE 9:e90634.

Peterson DS, Pickett KA, Duncan RP, Perlmutter JS, Earhart GM (2014b), Brain activity during complex imagined gait tasks in Parkinson disease. Clin Neurophysiol 125:9951005.

Pierrot-Deseilligny C, Müri RM, Ploner CJ, Gaymard B, Rivaud-Péchoux S (2003), Cortical control of ocular saccades in humans: a model for motricity. Prog Brain Res $142: 3-17$.

Rubino A, Assogna F, Piras F, Di Battista ME, Imperiale F, Chiapponi C, Spalletta G, Meco G (2014), Does a volume reduction of the parietal lobe contribute to freezing of gait in Parkinson's disease? Parkinsonism Relat Disord 20:1101-1103.

Rushworth MFS, Johansen-Berg H, Göbel SM, Devlin JT (2003), The left parietal and premotor cortices: motor attention and selection. Neuroimage 20 Suppl 1:S89-S100.

Samuel M, Ceballos-Baumann AO, Blin J, Uema T, Boecker H, Passingham RE, Brooks DJ (1997), Evidence for lateral premotor and parietal overactivity in Parkinson's disease during sequential and bimanual movements. A PET study. Brain 120:963-976.

Schaafsma JD, Balash Y, Gurevich T, Bartels AL, Hausdorff JM, Giladi N (2003), Characterization of freezing of gait subtypes and the response of each to levodopa in Parkinson's disease. Eur J Neurol 10:391-398.

Schluter ND, Krams M, Rushworth MF, Passingham RE (2001), Cerebral dominance for action in the human brain: the selection of actions. Neuropsychologia 39:105-113. 
Freezing of gait in PD: brain metabolism

Schluter ND, Rushworth MF, Passingham RE, Mills KR (1998), Temporary interference in human lateral premotor cortex suggests dominance for the selection of movements. A study using transcranial magnetic stimulation. Brain 121:785-799.

Schmidt R, Freidl W, Fazekas F, Reinhart B, Grieshofer P, Koch M, Eber B, Schumacher M, Polmin K, Lechner H (1994), The Mattis Dementia Rating Scale: normative data from 1,001 healthy volunteers. Neurology 44:964-966.

Schrader C, Peschel T, Däuper J, Rollnik JD, Dengler R, Kossev AR (2008), Changes in processing of proprioceptive information in Parkinson's disease and multiple system atrophy. Clin Neurophysiol 119:1139-1146.

Schweder PM, Hansen PC, Green AL, Quaghebeur G, Stein J, Aziz TZ (2010), Connectivity of the pedunculopontine nucleus in parkinsonian freezing of gait. Neuroreport 21:914-916.

Shimoji K, Ravasi L, Schmidt K, Soto-Montenegro ML, Esaki T, Seidel J, Jagoda E, Sokoloff L, Green MV, Eckelman WC (2004), Measurement of cerebral glucose metabolic rates in the anesthetized rat by dynamic scanning with 18F-FDG, the ATLAS small animal PET scanner, and arterial blood sampling. J Nucl Med 45:665-672.

Shine JM, Matar E, Ward PB, Bolitho SJ, Gilat M, Pearson M, Naismith SL, Lewis SJG (2013a), Exploring the cortical and subcortical functional magnetic resonance imaging changes associated with freezing in Parkinson's disease. Brain 136:1204-1215.

Shine JM, Matar E, Ward PB, Bolitho SJ, Pearson M, Naismith SL, Lewis SJG (2013b), Differential neural activation patterns in patients with Parkinson's disease and freezing of gait in response to concurrent cognitive and motor load. PLoS ONE 8:e52602.

Shine JM, Matar E, Ward PB, Frank MJ, Moustafa AA, Pearson M, Naismith SL, Lewis SJG (2013c), Freezing of gait in Parkinson's disease is associated with functional 
decoupling between the cognitive control network and the basal ganglia. Brain 136:36713681.

Shine JM, Moore ST, Bolitho SJ, Morris TR, Dilda V, Naismith SL, Lewis SJG (2012), Assessing the utility of Freezing of Gait Questionnaires in Parkinson's Disease. Parkinsonism Relat Disord 18:25-29.

Shine JM, Moustafa AA, Matar E, Frank MJ, Lewis SJG (2013d), The role of frontostriatal impairment in freezing of gait in Parkinson's disease. Front Syst Neurosci 7:61.

Shine JM, Naismith SL, Lewis SJG (2011a), The pathophysiological mechanisms underlying freezing of gait in Parkinson's Disease. J Clin Neurosci 18:1154-1157.

Shine JM, Ward PB, Naismith SL, Pearson M, Lewis SJG (2011b), Utilising functional MRI (fMRI) to explore the freezing phenomenon in Parkinson's disease. J Clin Neurosci $18: 807-810$.

Shulman GL, Tansy AP, Kincade M, Petersen SE, McAvoy MP, Corbetta M (2002), Reactivation of networks involved in preparatory states. Cereb Cortex 12:590-600.

Smith JB, Radhakrishnan H, Alloway KD (2012), Rat Claustrum Coordinates but Does Not Integrate Somatosensory and Motor Cortical Information. J Neurosci 32:8583-8588.

Snijders AH, Leunissen I, Bakker M, Overeem S, Helmich RC, Bloem BR, Toni I (2011), Gait-related cerebral alterations in patients with Parkinson's disease with freezing of gait. Brain 134:59-72.

Snijders AH, Nijkrake MJ, Bakker M, Munneke M, Wind C, Bloem BR (2008), Clinimetrics of freezing of gait. Mov Disord 23 Suppl 2:S468-S474.

Sockeel P, Dujardin K, Devos D, Denève C, Destée A, Defebvre L (2006), The Lille apathy rating scale (LARS), a new instrument for detecting and quantifying apathy: validation in Parkinson's disease. J Neurol Neurosurg Psychiatr 77:579-584. 
Sokoloff L, Reivich M, Kennedy C, Des Rosiers MH, Patlak CS, Pettigrew KD, Sakurada O, Shinohara M (1977), The [14C]deoxyglucose method for the measurement of local cerebral glucose utilization: theory, procedure, and normal values in the conscious and anesthetized albino rat. J Neurochem 28:897-916.

Sunwoo MK, Cho KH, Hong JY, Lee JE, Sohn YH, Lee PH (2013), Thalamic volume and related visual recognition are associated with freezing of gait in non-demented patients with Parkinson's disease. Parkinsonism Relat Disord 19:1106-1109.

Tanné-Gariépy J, Boussaoud D, Rouiller EM (2002), Projections of the claustrum to the primary motor, premotor, and prefrontal cortices in the macaque monkey. J Comp Neurol 454:140-157.

Tan T, Almeida QJ, Rahimi F (2011), Proprioceptive deficits in Parkinson's disease patients with freezing of gait. Neuroscience 192:746-752.

Taylor PCJ, Nobre AC, Rushworth MFS (2007), Subsecond changes in top down control exerted by human medial frontal cortex during conflict and action selection: a combined transcranial magnetic stimulation electroencephalography study. J Neurosci 27:1134311353.

Tessitore A, Amboni M, Cirillo G, Corbo D, Picillo M, Russo A, Vitale C, Santangelo G, Erro R, Cirillo M, Esposito F, Barone P, Tedeschi G (2012a), Regional gray matter atrophy in patients with Parkinson disease and freezing of gait. AJNR Am J Neuroradiol 33:18041809.

Tessitore A, Amboni M, Esposito F, Russo A, Picillo M, Marcuccio L, Pellecchia MT, Vitale C, Cirillo M, Tedeschi G, Barone P (2012b), Resting-state brain connectivity in patients with Parkinson's disease and freezing of gait. Parkinsonism Relat Disord 18:781787.Turner RS, Grafton ST, McIntosh AR, DeLong MR, Hoffman JM (2003), The functional anatomy of parkinsonian bradykinesia. Neuroimage 19:163-179. 
Freezing of gait in PD: brain metabolism

Vandenbossche J, Deroost N, Soetens E, Spildooren J, Vercruysse S, Nieuwboer A, Kerckhofs E (2011), Freezing of Gait in Parkinson Disease Is Associated With Impaired Conflict Resolution. Neurorehabil Neural Repair 25:765-773.

van der Hoorn A, Renken RJ, Leenders KL, de Jong BM (2014), Parkinson-related changes of activation in visuomotor brain regions during perceived forward self-motion. PLoS ONE 9:e95861.

van der Meulen M, Allali G, Rieger SW, Assal F, Vuilleumier P (2014), The influence of individual motor imagery ability on cerebral recruitment during gait imagery. Hum Brain Mapp 35:455-470.

Vercruysse S, Gilat M, Shine JM, Heremans E, Lewis S, Nieuwboer A (2014b), Freezing beyond gait in Parkinson's disease: A review of current neurobehavioral evidence. Neurosci Biobehav Rev 43C:213-227.

Vercruysse S, Spildooren J, Heremans E, Vandenbossche J, Levin O, Wenderoth N, Swinnen SP, Janssens L, Vandenberghe W, Nieuwboer A (2012), Freezing in Parkinson's disease: A spatiotemporal motor disorder beyond gait. Mov Disord 27:254-263.

Vercruysse S, Spildooren J, Heremans E, Wenderoth N, Swinnen SP, Vandenberghe W, Nieuwboer A (2014a), The Neural Correlates of Upper Limb Motor Blocks in Parkinson's Disease and Their Relation to Freezing of Gait. Cereb Cortex 24:3154-3166.

Vervoort G, Nackaerts E, Mohammadi F, Heremans E, Verschueren S, Nieuwboer A, Vercruysse S (2013), Which Aspects of Postural Control Differentiate between Patients with Parkinson's Disease with and without Freezing of Gait? Parkinsons Dis 2013:971480. Wise SP, Boussaoud D, Johnson PB, Caminiti R (1997), Premotor and parietal cortex: corticocortical connectivity and combinatorial computations. Annu Rev Neurosci 20:2542. 
Freezing of gait in PD: brain metabolism

Yang Z, Mayer AR (2014), An event-related FMRI study of exogenous orienting across vision and audition. Hum Brain Mapp 35:964-974.

Yogev-Seligmann G, Hausdorff JM, Giladi N (2008), The role of executive function and attention in gait. Mov Disord 23:329-342.

Youn J, Lee J-M, Kwon H, Kim JS, Son TO, Cho JW (2015), Alternations of mean diffusivity of pedunculopontine nucleus pathway in Parkinson's disease patients with freezing of gait. Parkinsonism Relat Disord 21:12-17.

Zacks JM, Swallow KM (2007), Event segmentation. Curr Dir Psychol Sci 16:80-84.

Zwergal A, la Fougère C, Lorenzl S, Rominger A, Xiong G, Deutschenbaur L, Schöberl F, Linn J, Dieterich M, Brandt T, Strupp M, Bartenstein P, Jahn K (2013), Functional disturbance of the locomotor network in progressive supranuclear palsy. Neurology 80:634-641. 


\section{Freezing of gait in PD: brain metabolism}

Figure captions

Figure 1: schema of the PET acquisitions

Figure 2: Significant differences $(\mathrm{p}<0.005)$ in metabolism when comparing the two experimental conditions (modulated gait vs. resting) in the non-FoG group (left panel) and FoG (right panel) group. Note that both groups of PD patients displayed hypermetabolism in the cerebellum, sensory areas, prefrontal areas, temporoparietal junction and cingulate cortex after performing FoG trajectories. As detailed in Table 4, basal ganglia activation during gait was significant in the FoG group only. The colour scales correspond to the Zscores.

Figure 3: Significant differences $(\mathrm{p}<0.005)$ in metabolism when comparing gait in FoG and non-FoG groups of PD patients. Hypermetabolism was observed in the right rostral SMA, right temporopolar area and right orbitofrontal area in the non-FoG group and in the left intraparietal sulcus and paracentral lobule in the FoG group (from top to bottom). The colour scales correspond to the Z-scores.

Figure 4: Correlations between brain metabolism after the gait session (taking account all the subjects) and gait subscores of Unified Parkinson's Disease Rating Scale part III (offdrug). 
Gait session (see also supplemental video)

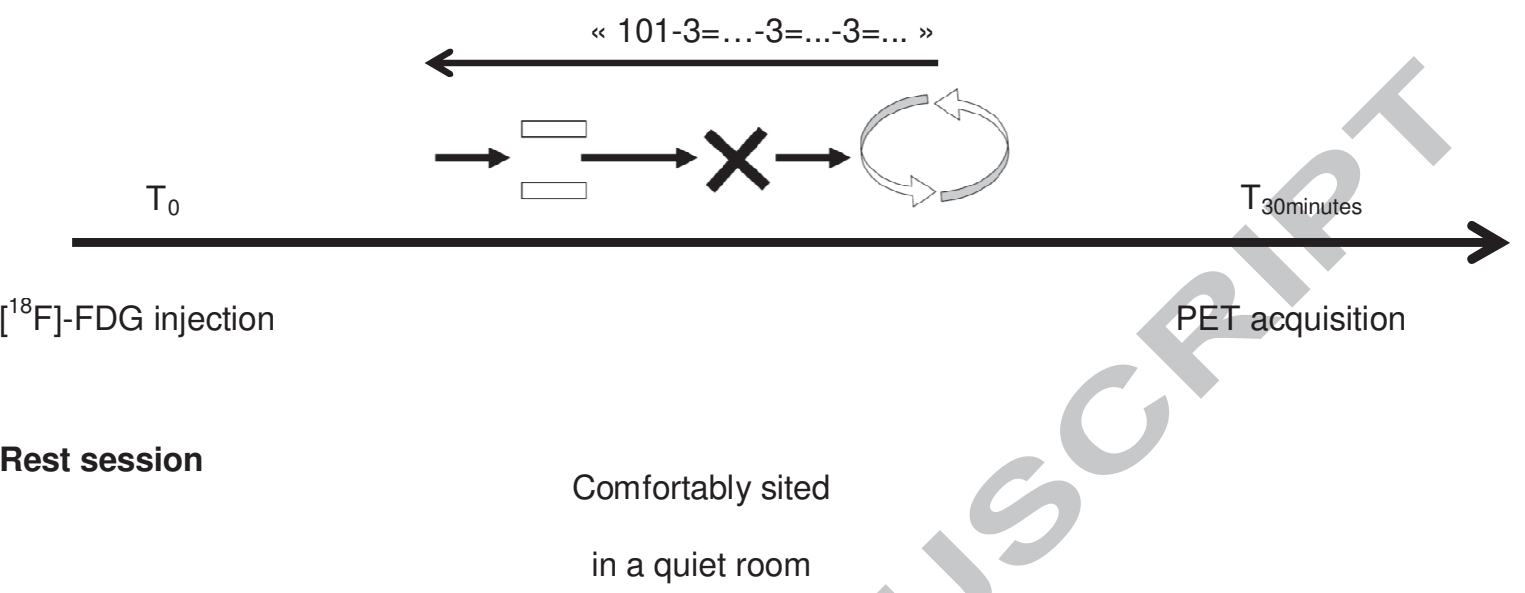


Legend: The double bars indicate the narrow space, the cross indicates a stop (feet together), followed by a further gait initiation (self-initiated), the arrows indicate the series of turns on him/herself (right and left, normal and fast speeds) and finally the return with mental decounting. 


\section{ACCEPTED MANUSCRIPT}
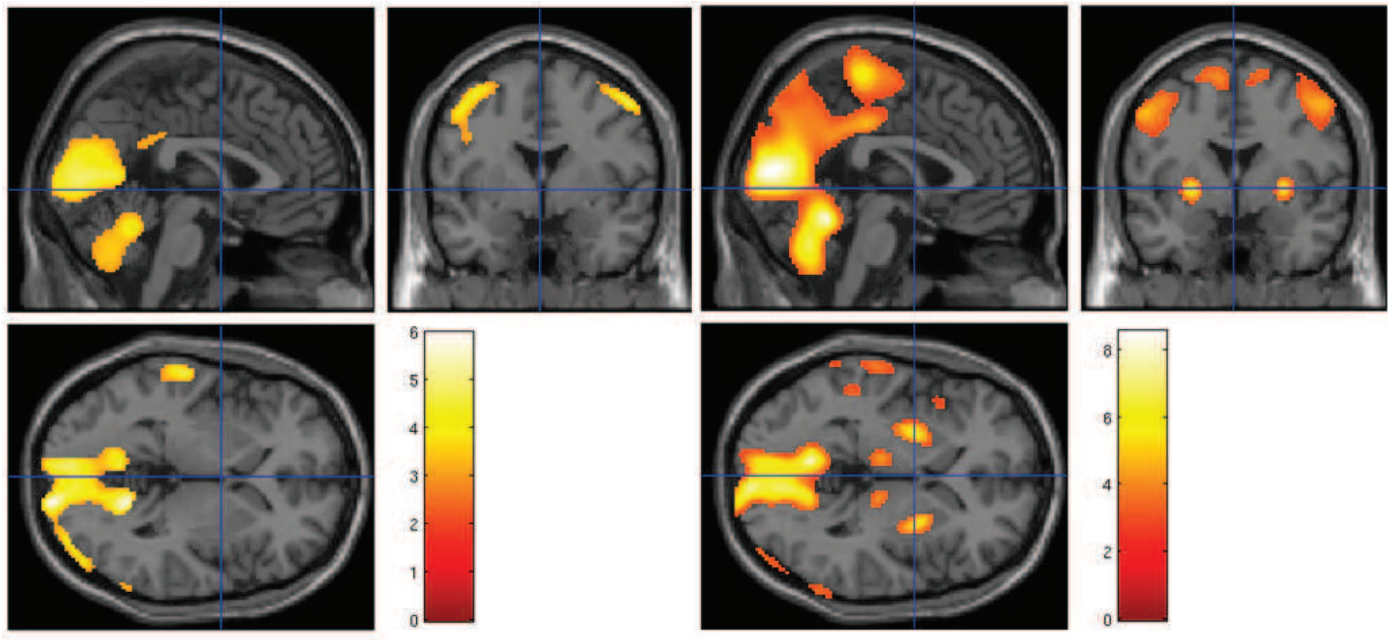

FOG-: gait>resting

FOG+: gait>resting 


\section{ACCEPTED MANUSCRIPT}

Freezing of gait in PD: brain metabolism

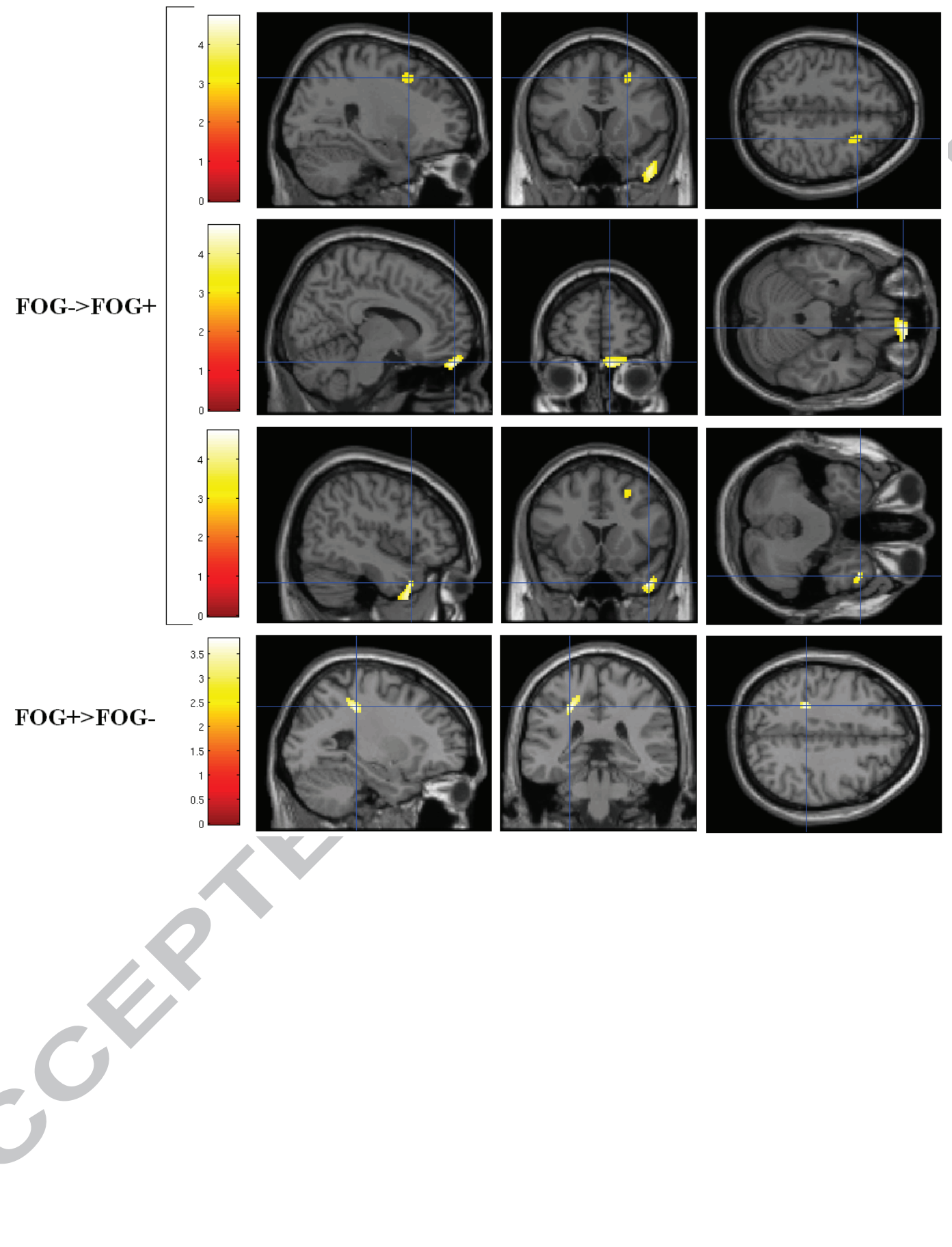




\section{ACC.EPTED MANUSCRIPI}

Freezing of gait in PD: brain metabolism

\section{Correlations with gait subscores (UPDRS 3)}

Positive with mainly the parietal cortex (inferior parietal lobule) and basal ganglia
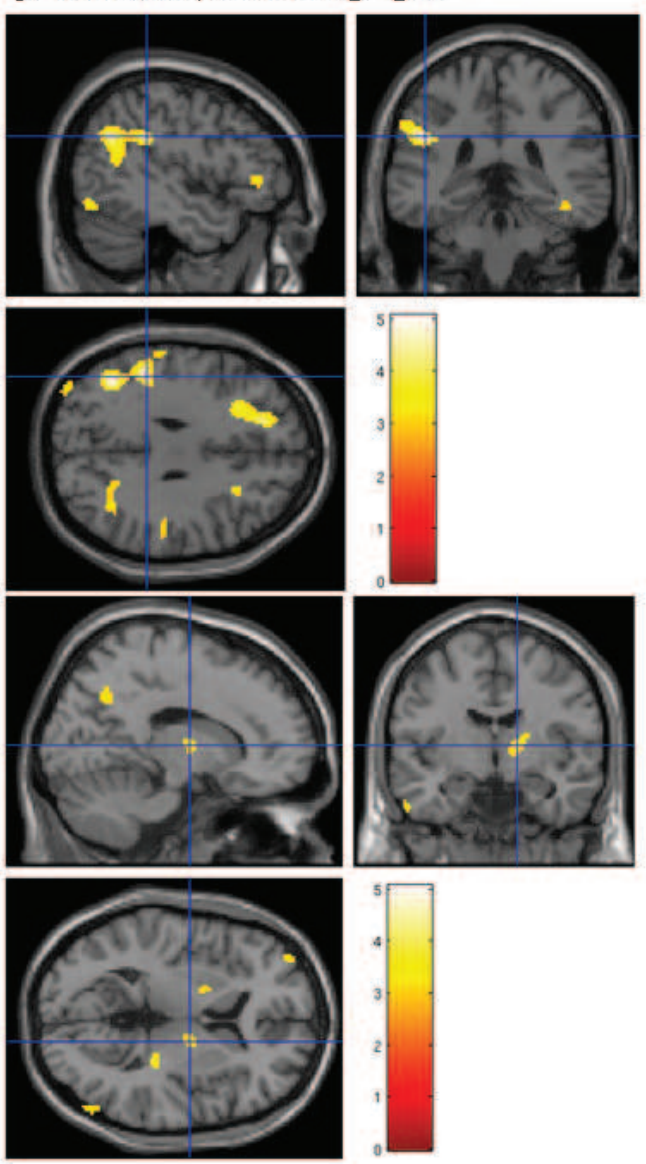

Negative with mainly the premotor area and the cingulate gyrus
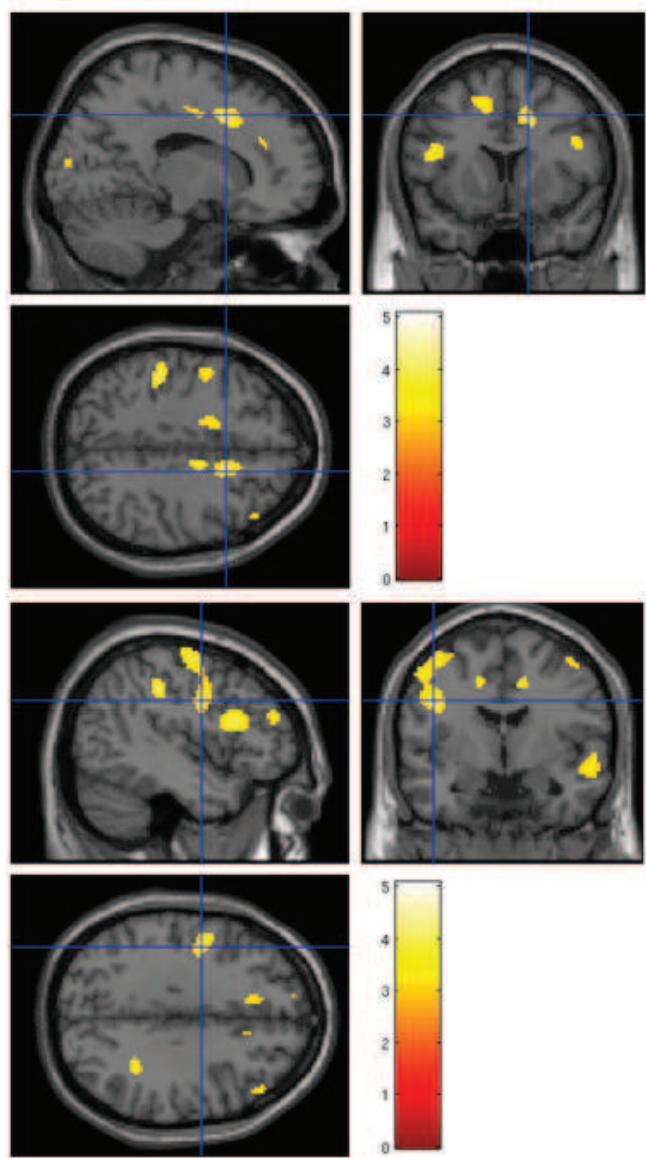
Freezing of gait in PD: brain metabolism

Table 1-A: The demographic, neuropsychological and clinical characteristics of the study subgroups, and statistical comparisons.

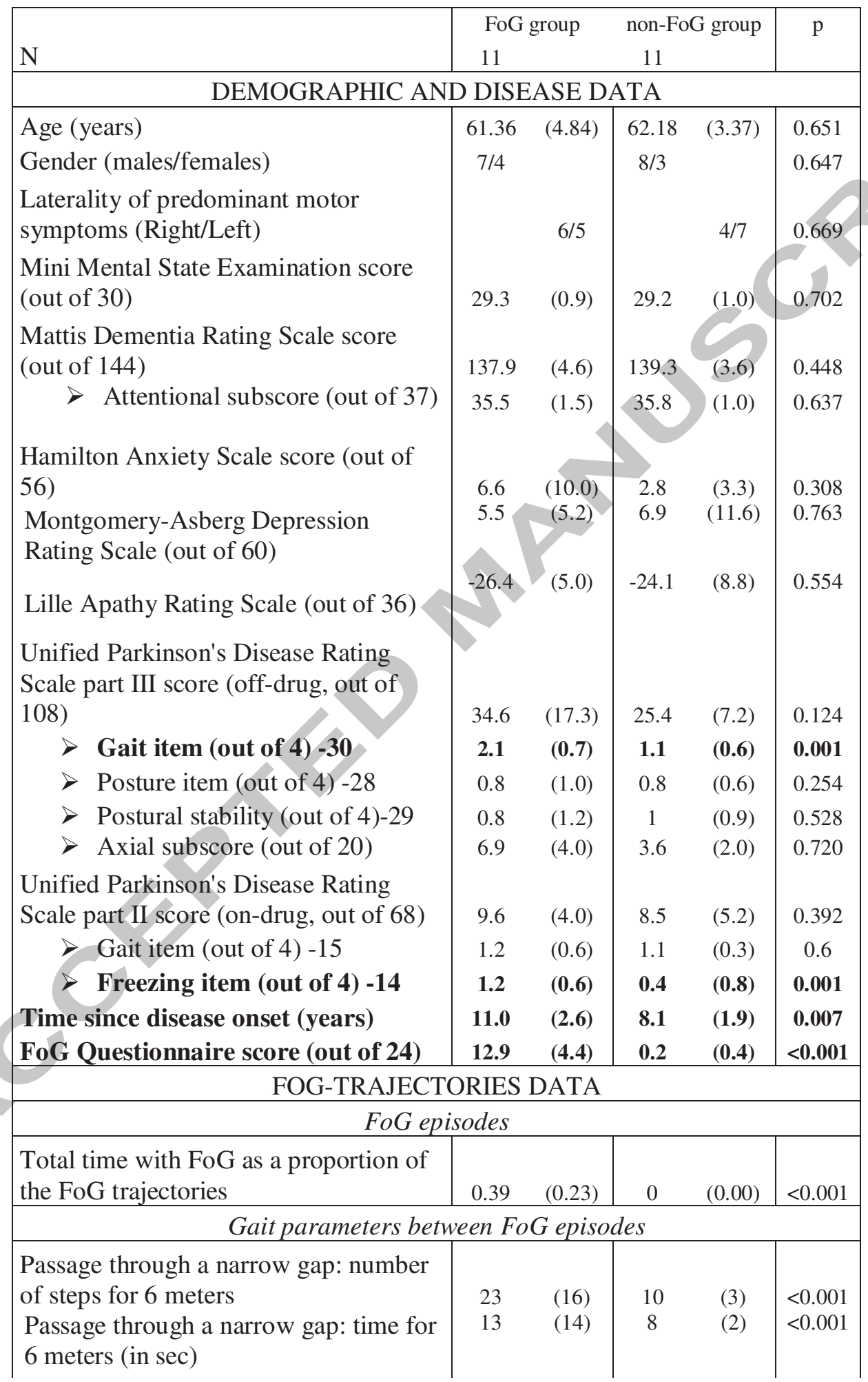




\section{Freezing of gait in PD: brain metabolism}

\section{ACCEPTED MANUSCRIPT}

Dual task with counting: number of steps for 6 meters

Dual task with counting: time for 6 meters (in sec)

\begin{tabular}{ll|ll|l|}
62 & $(37)$ & 10 & $(3)$ & $<0.001$ \\
28 & $(14)$ & 8 & $(3)$ & $<0.001$ \\
\hline
\end{tabular}

Data are quoted as the mean (standard deviation).

The axial motor subscore was defined as the sum of items 18, 27, 28, 29 and 30 of the Unified Parkinson's Disease Rating Scale part III (speech, rising from a chair, posture, gait and postural stability).

Table 1-B: Antiparkinsonian treatments of the two groups (FoG and non-FoG group). For levodopa equivalent dose daily, the results were presented as mean (standard deviation) and for others treatments, $\%$ of patients.

\begin{tabular}{|c|c|c|}
\hline & FoG group & non-FoG group \\
\hline Levodopa & $100 \%$ & $100 \%$ \\
\hline COMT inhibitors & $73 \%$ & $64 \%$ \\
\hline Dopaminergic agonists & $91 \%$ & $82 \%$ \\
\hline Amantadine & $18 \%$ & $0 \%$ \\
\hline Monoamine oxydase inhibitors & $0 \%$ & $45 \%$ \\
\hline Anticholinergics & $0 \%$ & $9 \%$ \\
\hline Benzodiazepines & $27 \%$ & $9 \%$ \\
\hline Inhibitors of serotonin reuptake & $9 \%$ & $9 \%$ \\
\hline levodopa equivalent dose (mg/day) & $1129(344)$ & $807(182)$ \\
\hline
\end{tabular}


Freezing of gait in PD: brain metabolism

Table 2: correlations between FoG scores and motor scores.

\begin{tabular}{|c|c|c|c|c|c|}
\hline & & \multicolumn{2}{|c|}{ Percent time with FoG } & \multicolumn{2}{|c|}{ FoG-Questionnaire } \\
\hline & & $\begin{array}{l}\text { Pearson } \\
\text { Correlation }\end{array}$ & Signifiance & $\begin{array}{l}\text { Pearson } \\
\text { Correlation }\end{array}$ & Signifiance \\
\hline \multirow{5}{*}{$\begin{array}{c}\text { UPDRS } 3 \\
\text { in off drug } \\
\text { state }\end{array}$} & Total motor score & 0.506 & 0.016 & 0.604 & 0.003 \\
\hline & Axial subscore & 0.564 & 0.006 & 0.560 & 0.007 \\
\hline & Gait & 0.754 & 0.000 & 0.783 & 0.000 \\
\hline & Posture & 0.445 & 0.043 & 0.344 & 0.127 \\
\hline & Postural stability & 0.337 & 0.135 & 0.243 & 0.288 \\
\hline \multirow{3}{*}{$\begin{array}{l}\text { UPDRS } 2 \\
\text { in on state }\end{array}$} & $\begin{array}{l}\text { Total daily life } \\
\text { score }\end{array}$ & 0.122 & 0.590 & 0.229 & 0.306 \\
\hline & Freezing & 0.458 & 0.032 & 0.622 & 0.002 \\
\hline & Gait & 0.219 & 0.340 & 0.222 & 0.333 \\
\hline \multirow{3}{*}{$\begin{array}{c}\text { FoG } \\
\text { parameters }\end{array}$} & $\begin{array}{l}\text { Percent time with } \\
\text { FoG }\end{array}$ & & & & 0.000 \\
\hline & FoG-Questionnaire & 0.776 & 0.000 & & \\
\hline & Item 3 of FoG-Q & 0.636 & 0.001 & 0.840 & 0.000 \\
\hline
\end{tabular}


Table 3: Results of an SPM analysis concerning the effect of group and condition and posthoc analyses.

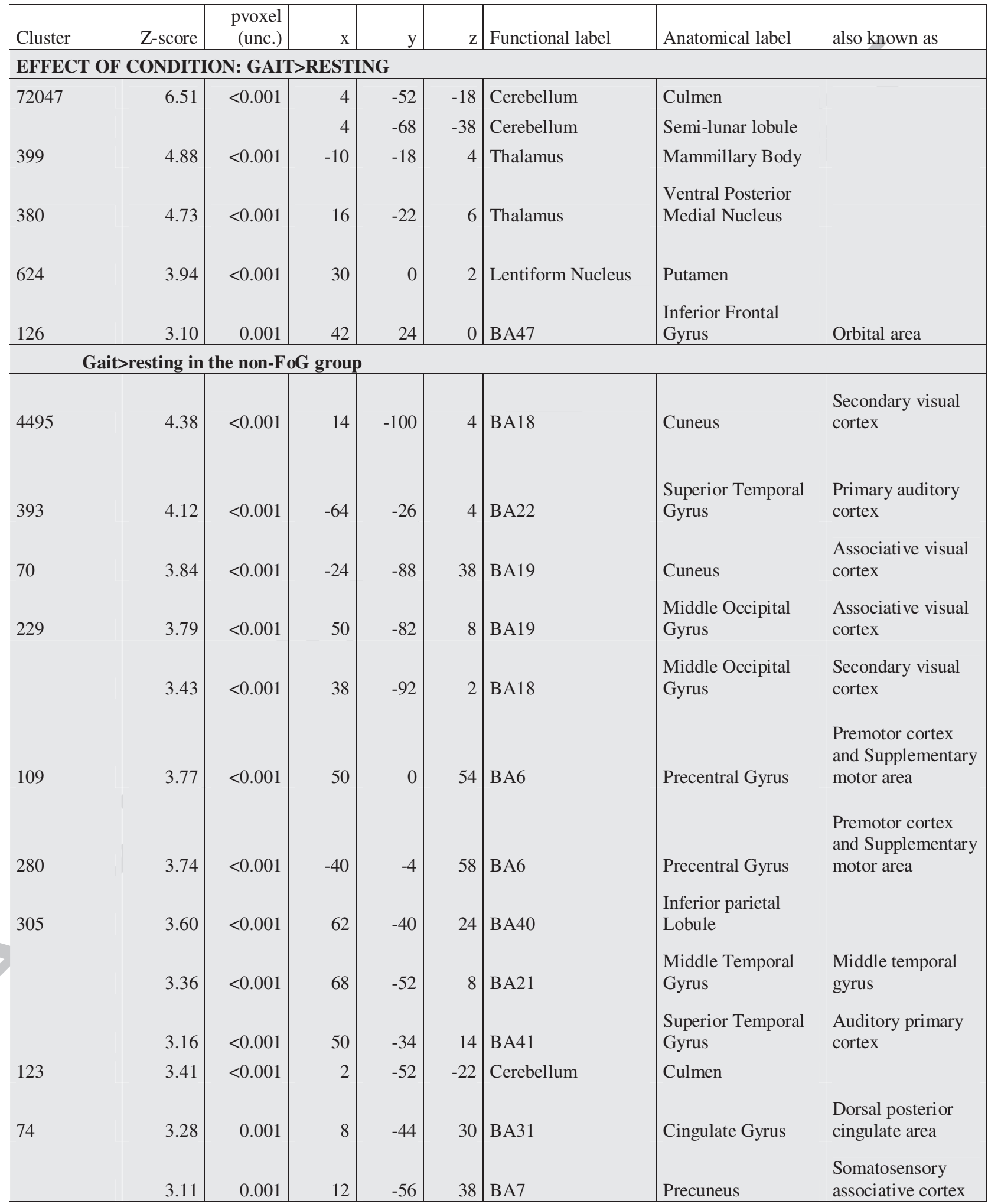




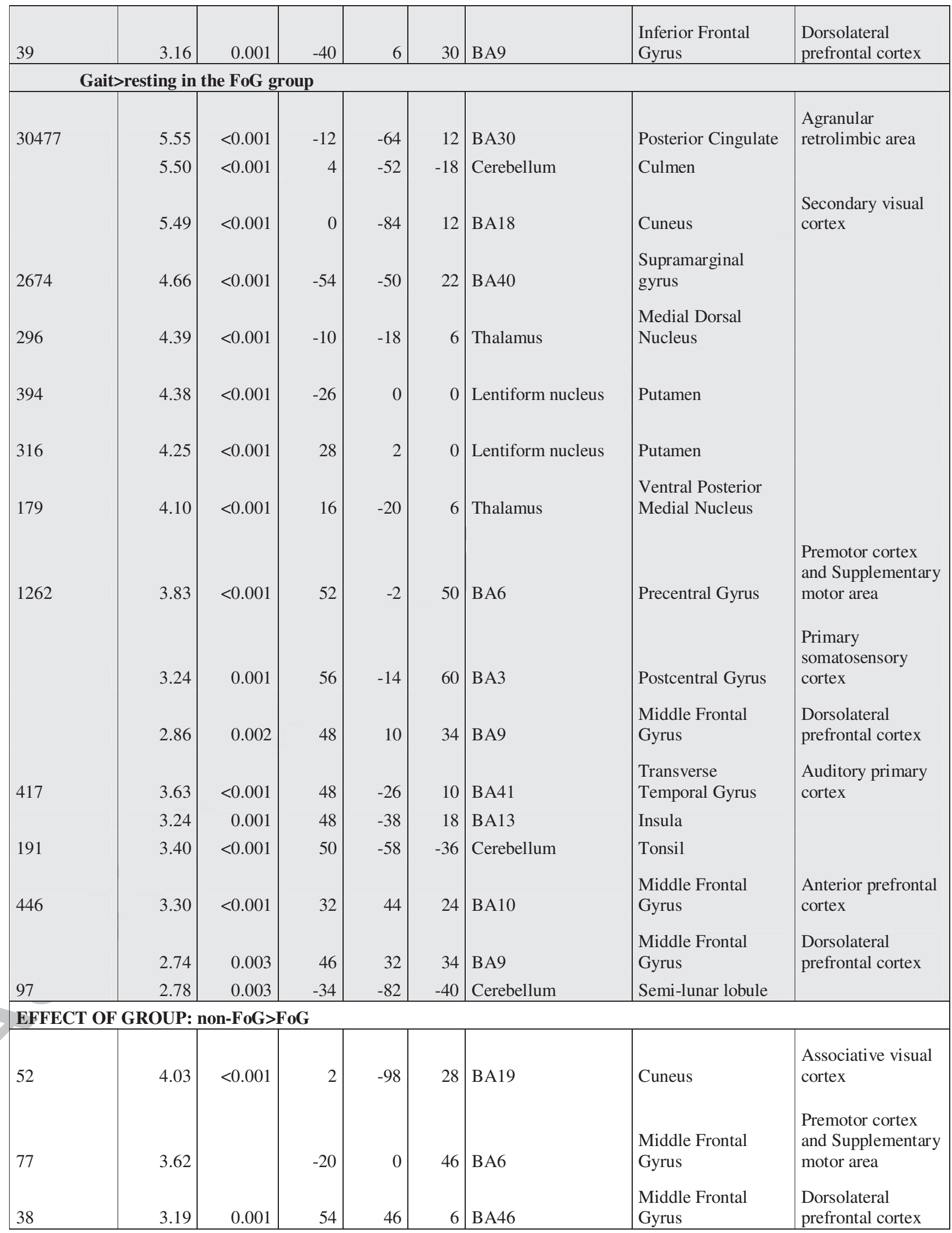




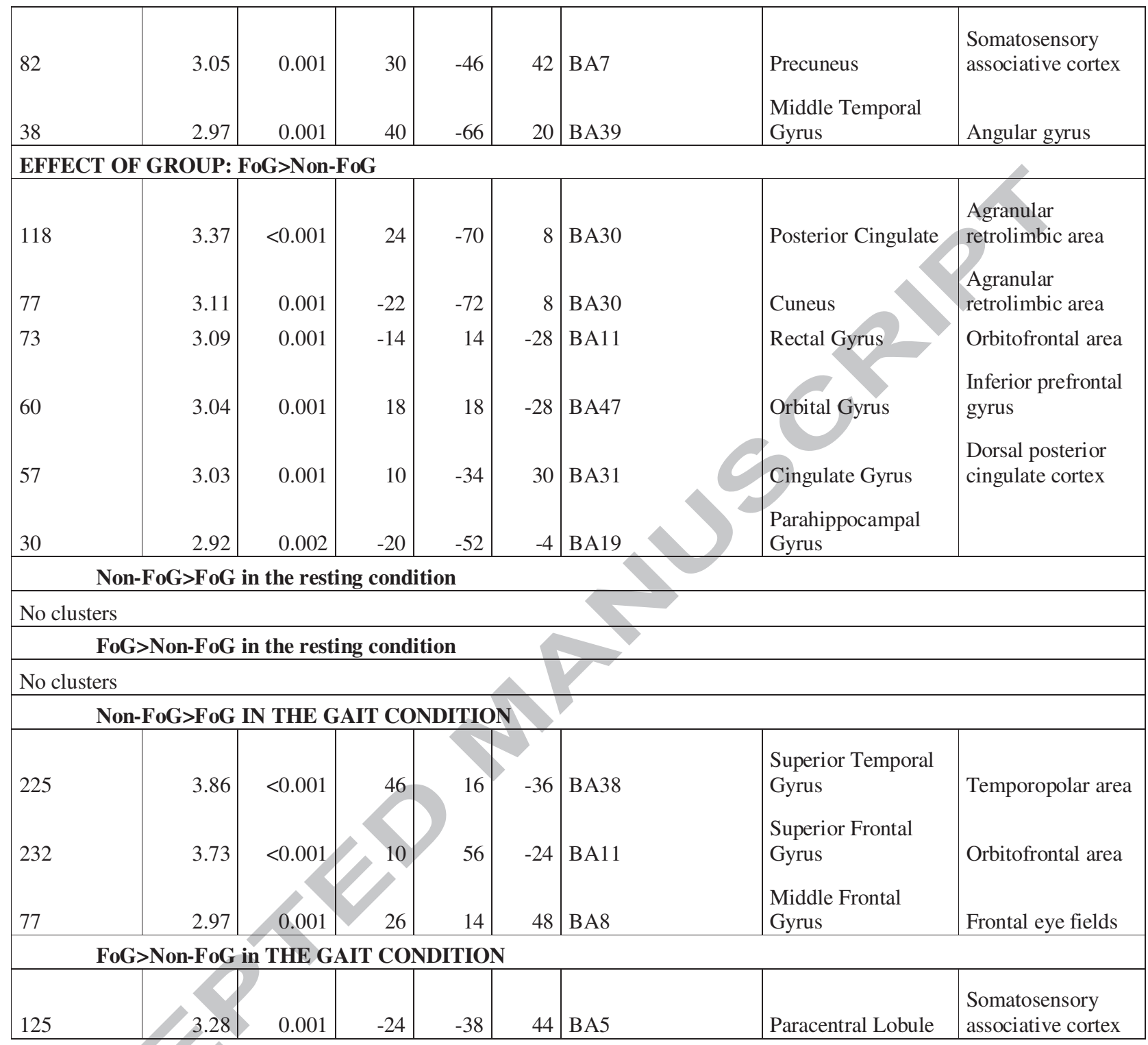

The "Cluster" column indicates the number of voxels in the significant area. Coordinates (x; y; z) are presented in Talairach space.

Threshold of at least 30 contiguous voxels were applied for clusters, with a two-tailed $\mathrm{p}$ value of 0.005 . Local maxima more than $8 \mathrm{~mm}$ apart were reported only if the corresponding area was different.

First, in greyed out are represented results of gait activation that is hypermetabolic regions during gait by comparing with rest (distinctly between groups, see Figure 1). Secondly are 
represented the major results of our study, that is differences between FoG-group and nonFoG group (see Figure 2). Coordinates are given in the Talairach space.

BA: Brodmann area / unc: uncorrected 
Table 4: Results of an SPM analysis concerning the ROI.

\begin{tabular}{|c|c|c|c|c|c|c|c|c|}
\hline \multirow{2}{*}{$\begin{array}{l}\text { Group } \\
\text { Coordonnates (peak) }\end{array}$} & \multicolumn{3}{|c|}{ non-FoG } & \multirow{2}{*}{$\begin{array}{l}\text { pvoxel } \\
\text { (unc.) }\end{array}$} & \multicolumn{3}{|c|}{ FoG } & \multirow[t]{2}{*}{ pvoxel } \\
\hline & $\mathrm{x}$ & $\mathrm{y}$ & $\mathrm{Z}$ & & $\mathrm{x}$ & $\mathrm{y}$ & $\mathrm{Z}$ & \\
\hline \multicolumn{9}{|c|}{ Cortical structures showing activation during gait comparing with rest } \\
\hline \multirow[t]{2}{*}{ Primary motor cortex } & 8 & -23 & 64 & 0.004 & 2 & -26 & 61 & $<0.001$ \\
\hline & -10 & -24 & 61 & 0.002 & -8 & & 63 & $<0.001$ \\
\hline \multirow[t]{2}{*}{ Dorsal premotor area } & 14 & -9 & 63 & 0.029 & & -13 & 63 & $<0.001$ \\
\hline & -20 & -13 & 64 & 0.006 & -14 & -13 & 63 & $<0.001$ \\
\hline \multicolumn{9}{|l|}{ Dorsolateral prefrontal } \\
\hline \multirow[t]{2}{*}{ cortex } & 45 & 29 & 30 & 0.006 & 45 & 29 & 30 & 0.006 \\
\hline & & 22 & 29 & 0.007 & -39 & 21 & 27 & 0.001 \\
\hline \multirow{4}{*}{$\begin{array}{l}\text { Medial prefrontal cortex } \\
\text { Posterior parietal cortex }\end{array}$} & & & 33 & 0.014 & \multicolumn{4}{|c|}{ No right peak } \\
\hline & & 18 & 33 & 0.014 & \multicolumn{4}{|c|}{ No left peak } \\
\hline & 55 & -48 & 45 & 0.028 & 57 & -46 & 46 & 0.02 \\
\hline & -56 & -47 & 47 & 0.018 & -54 & -49 & 47 & 0.001 \\
\hline \multicolumn{9}{|c|}{ Cortical structures showing deactivation during gait comparing with rest } \\
\hline \multirow{2}{*}{ Medial prefrontal cortex } & & & & & \multicolumn{4}{|c|}{ No right peak } \\
\hline & & & & & -9 & 15 & 28 & 0.088 \\
\hline \multicolumn{9}{|c|}{ Sub-cortical structures showing activation during gait comparing with rest } \\
\hline \multirow[t]{2}{*}{ Subthalamic nucleus } & 7 & -17 & 5 & 0.003 & 11 & -17 & 5 & $<0.001$ \\
\hline & -7 & -17 & 5 & $\mathbf{0 . 0 0 5}$ & -9 & -17 & 5 & $<0.001$ \\
\hline Thalamus & 7 & -15 & 7 & 0.003 & 7 & -15 & 7 & 0.016 \\
\hline
\end{tabular}




\begin{tabular}{|c|c|c|c|c|c|c|c|c|}
\hline & 7 & 15 & 7 & 0008 & 7 & 15 & & 0001 \\
\hline Putamen & 25 & 0 & 5 & 0.012 & 27 & 0 & 5 & $<0.001$ \\
\hline & -25 & 0 & 4 & 0.033 & -25 & 0 & 4 & $<0.001$ \\
\hline Sub-cortical str & wing & leact & tion & during & ait & npa & ng & \\
\hline Globus pallidus & 12 & -4 & 3 & 0.024 & 12 & -4 & 3 & 0.002 \\
\hline & -12 & -2 & 3 & 0.025 & No & eft $p$ & & \\
\hline Caudate nucleus & No & ght 1 & & & 13 & & & 0.082 \\
\hline & & eft $p$ & & & & eft $p$ & & \\
\hline Ventral striatum & 5 & 9 & -4 & 0.015 & & 9 & -4 & 0.022 \\
\hline & -8 & 3 & -2 & 0.01 & & eft $p$ & & \\
\hline MLR & 5 & -29 & -14 & 0.041 & 2 & -29 & -14 & 0.002 \\
\hline & -1 & -29 & -14 & 0.069 & -5 & -29 & -14 & $<0.001$ \\
\hline
\end{tabular}

Coordinates $(\mathrm{x} ; \mathrm{y} ; \mathrm{z})$ are presented in Talairach space. Significant $\mathrm{p}$-values are highlighted in bold type.

unc: uncorrected 
Table 5: Comparison of brain metabolism in FoG and non-FoG patients after gait by adding covariates (gender and disease duration). Coordinates are given in the Talairach space.

\begin{tabular}{|c|c|c|c|c|c|c|c|c|}
\hline Cluster & $\begin{array}{r}\text { Z- } \\
\text { score }\end{array}$ & $\begin{array}{r}\mathrm{p} \\
\text { (unc.) }\end{array}$ & $\mathrm{x}$ & $\mathrm{y}$ & $\mathrm{z}$ & Functional label & Anatomical label & also known as \\
\hline \multicolumn{9}{|c|}{ non-FoG>FoG in gait condition with covariates (gender and disease duration) } \\
\hline 510 & 3.92 & $<0.001$ & -36 & -58 & 48 & BA7 & $\begin{array}{l}\text { Superior Parietal Lobule } \\
\text { Superior Temporal }\end{array}$ & Somatosensory Association Cortex \\
\hline 100 & 3.47 & $<0.001$ & -42 & -34 & 16 & BA41 & Gyrus & Premotor cortey and Sunnlementary \\
\hline 875 & 3.35 & $<0.001$ & $\begin{array}{l}37 \\
18\end{array}$ & $\begin{array}{r}1 \\
23\end{array}$ & $\begin{array}{l}57 \\
46\end{array}$ & $\begin{array}{l}\text { BA6 } \\
\text { BA8 }\end{array}$ & $\begin{array}{l}\text { Middle Frontal Gyrus } \\
\text { Superior Frontal Gyrus }\end{array}$ & $\begin{array}{l}\text { motor area } \\
\text { Frontal eye fields }\end{array}$ \\
\hline 373 & 3.33 & $<0.001$ & $\begin{array}{l}29 \\
43\end{array}$ & $\begin{array}{l}-67 \\
-52\end{array}$ & $\begin{array}{l}50 \\
46\end{array}$ & $\begin{array}{l}\text { BA7 } \\
\text { BA40 }\end{array}$ & $\begin{array}{l}\text { Superior Parietal Lobule } \\
\text { Inferior Parietal Lobule }\end{array}$ & $\begin{array}{l}\text { Somatosensory Association Cortex } \\
\text { Supramarginal gyrus }\end{array}$ \\
\hline 83 & 3.27 & $<0.001$ & 15 & -61 & 62 & BA7 & Superior Parietal Lobule & Somatosensory Association Cortex \\
\hline 60 & 3.11 & 0.001 & 13 & 50 & -24 & BA11 & Superior Frontal Gyrus & Orbitofrontal area \\
\hline 53 & 3.06 & 0.001 & -34 & -91 & 8 & BA19 & Middle Occipital Gyrus & Associative visual cortex \\
\hline 67 & 3.04 & 0.001 & 41 & 1 & -40 & BA38 & Middle Temporal Gyrus & Temporopolar area \\
\hline 64 & 2.91 & 0.002 & -36 & -4 & -31 & BA21 & $\begin{array}{l}\text { Middle Temporal Gyrus } \\
\text { Middle Frontal Gyrus }\end{array}$ & $\begin{array}{l}\text { Premotor cortex and Supplementary } \\
\text { motor area }\end{array}$ \\
\hline 40 & 2.90 & 0.002 & 26 & 42 & 47 & BA8 & Superior Frontal Gyrus & Frontal eye fields \\
\hline 85 & 2.88 & 0.002 & -4 & -83 & 27 & BA19 & Cuneus & $\begin{array}{l}\text { Associative visual cortex } \\
\text { Premotor cortex and Sunplementary }\end{array}$ \\
\hline \multirow[t]{2}{*}{92} & 2.88 & 0.002 & -18 & 13 & 53 & BA6 & Superior Frontal Gyrus & motor area \\
\hline & & & -15 & 21 & 49 & BA8 & Superior Frontal Gyrus & Frontal eye fields \\
\hline 75 & 2.87 & 0.002 & 8 & -83 & 42 & BA19 & Precuneus & Associative visual cortex \\
\hline 34 & 2.84 & 0.002 & -8 & 31 & 29 & BA32 & Cingulate gyrus & Dorsal anterior cingulate cortex \\
\hline 36 & 2.81 & 0.003 & -50 & -64 & 22 & BA39 & Middle Temporal Gyrus & Angular gyrus \\
\hline 35 & 2.69 & 0.004 & -18 & -78 & 25 & BA18 & Cuneus & Secondary visual cortex \\
\hline \multicolumn{9}{|c|}{ FoG>non-FoG in gait condition with covariates (gender and disease duration) } \\
\hline 294 & 3.33 & $<0.001$ & $\begin{array}{l}36 \\
38\end{array}$ & $\begin{array}{l}22 \\
32\end{array}$ & $\begin{array}{l}-21 \\
-18\end{array}$ & $\begin{array}{l}\text { BA38 } \\
\text { BA47 }\end{array}$ & $\begin{array}{l}\text { Superior Temporal } \\
\text { Gyrus } \\
\text { Inferior Frontal Gyrus }\end{array}$ & $\begin{array}{l}\text { Temporopolar area } \\
\text { Pars orbitalis }\end{array}$ \\
\hline 44 & 3.30 & $<0.001$ & -23 & 14 & 13 & Claustrum & & \\
\hline 59 & 3.00 & 0.001 & 12 & -96 & -11 & BA17 & Lingual Gyrus & Primary visual Cortex \\
\hline 45 & 2.77 & 0.003 & 48 & -47 & -28 & Cerebellum & Anterior Lobe, culmen & \\
\hline
\end{tabular}


Table 6: Results of an SPM analysis concerning the correlations between metabolic activations and clinical variables (percentage time of FoG and gait items). Coordinates are given in the Talairach space.

\begin{tabular}{|c|c|c|c|c|c|c|c|c|}
\hline Cluster & $\begin{array}{r}\text { Z- } \\
\text { score }\end{array}$ & $\begin{array}{r}\mathrm{p} \\
\text { (unc.) }\end{array}$ & $\mathrm{x}$ & $\mathrm{y}$ & $\mathrm{z}$ & Functional label & Anatomical label & also known as \\
\hline \multicolumn{9}{|c|}{ POSITIVE CORRELATION with percentage time spent FoG during FoG-trajectory } \\
\hline 74 & 3.54 & $<0.001$ & 50 & -81 & -30 & Cerebellum & Posterior Lobe & Tuber \\
\hline 209 & 3.3 & $<0.001$ & 2 & -30 & 53 & BA5 & Paracentral Lobule & Somatosensory Association Cortex \\
\hline 80 & 3.09 & 0.001 & 5 & 42 & 47 & BA8 & Superior Frontal Gyrus & Frontal eye fields \\
\hline \multicolumn{9}{|c|}{ NEGATIVE CORRELATION with percentage time spent FoG during FoG-trajectory } \\
\hline 489 & 4.54 & $<0.001$ & -54 & -30 & -12 & BA20 & $\begin{array}{l}\text { Inferior Temporal } \\
\text { Gyrus } \\
\text { Superior Temporal }\end{array}$ & Ventral stream of visual processing \\
\hline & & & -59 & -9 & 8 & BA22 & Gyrus & Primary auditory cortex \\
\hline & & & -53 & -12 & -7 & BA22 & Middle Temporal Gyrus & \\
\hline 228 & 4.41 & $<0.001$ & -5 & -49 & 16 & BA30 & Posterior Cingulate & \\
\hline 164 & 3.93 & $<0.001$ & -24 & 58 & 21 & BA10 & Middle Frontal Gyrus & Anterior prefrontal cortex \\
\hline 84 & 3.27 & 0.001 & -40 & 12 & 17 & BA13 & Insula & \\
\hline \multirow[t]{3}{*}{244} & 3.18 & 0.001 & -32 & -33 & 55 & BA3 & Postcentral Gyrus & Primary Somatosensory Cortex \\
\hline & & & -44 & -29 & 46 & BA40 & Postcentral Gyrus & Supramarginal gyrus \\
\hline & & & -41 & -28 & 39 & BA40 & Inferior Parietal Lobule & Supramarginal gyrus \\
\hline 83 & 3.11 & 0.001 & -18 & 48 & -20 & BA11 & Superior Frontal Gyrus & Orbitofrontal area \\
\hline 30 & 3.11 & 0.001 & 32 & 23 & -14 & BA47 & Inferior Frontal Gyrus & Pars orbitalis \\
\hline 140 & 3.04 & 0.001 & -65 & -40 & 11 & BA22 & $\begin{array}{l}\text { Gyperior lemporal } \\
\text { Gyrus }\end{array}$ & Primary auditory cortex \\
\hline 39 & 3.01 & 0.001 & -30 & -35 & -18 & BA20 & Fusiform Gyrus & Ventral stream of visual processing \\
\hline \multirow[t]{3}{*}{125} & 2.89 & 0.002 & -24 & 28 & -17 & BA11 & Middle Frontal Gyrus & Orbitofrontal area \\
\hline & & & -35 & 23 & -11 & BA47 & Inferior Frontal Gyrus & Pars orbitalis \\
\hline & 2.85 & 0.002 & -32 & -9 & 49 & BA6 & & $\begin{array}{l}\text { Premotor cortex and Supplementary } \\
\text { Motor Area }\end{array}$ \\
\hline \multicolumn{9}{|c|}{ POSITIVE CORRELATION with gait subscore (UPDRS 3) } \\
\hline \multirow[t]{2}{*}{940} & 3.94 & $<0.001$ & -45 & -34 & 29 & & $\begin{array}{l}\text { Inferior Parietal Lobule } \\
\text { Superior Temporal }\end{array}$ & Supramarginal gyrus \\
\hline & & & & -56 & 30 & BA39 & Gyrus & Angular gyrus \\
\hline \multirow[t]{2}{*}{103} & 3.78 & $<0.001$ & 7 & 51 & 43 & BA8 & Superior Frontal Gyrus & Frontal eye fields \\
\hline & & & -10 & 50 & 37 & BA8 & Superior Frontal Gyrus & Frontal eye fields \\
\hline 84 & 3.76 & $<0.001$ & -41 & -72 & -9 & BA19 & Fusiform Gyrus & Associative visual cortex \\
\hline 77 & 3.62 & $<0.001$ & 31 & 63 & 14 & BA10 & Superior Frontal Gyrus & Anterior prefrontal cortex \\
\hline 163 & 3.53 & $<0.001$ & -23 & -15 & 36 & BA24 & Cingulate gyrus & Ventral anterior cingulate cortex \\
\hline \multirow[t]{2}{*}{489} & 3.51 & $<0.001$ & -18 & 39 & 26 & BA9 & Superior Frontal Gyrus & Dorsolateral prefrontal cortex \\
\hline & & & -27 & 22 & 30 & BA9 & Middle Frontal Gyrus & Dorsolateral prefrontal cortex \\
\hline \multirow[t]{3}{*}{266} & 3.39 & $<0.001$ & 39 & -42 & 21 & BA13 & Insula & \\
\hline & & & 20 & -55 & 34 & BA31 & Precuneus & Somatosensory associative cortex \\
\hline & & & 36 & -54 & 28 & BA39 & $\begin{array}{l}\text { Superior Temporal } \\
\text { Gyrus }\end{array}$ & Angular gyrus \\
\hline 82 & 3.39 & $<0.001$ & -32 & -91 & -16 & BA18 & Inferior Occipital Gyrus & Secondary visual cortex \\
\hline 60 & 3.31 & $<0.001$ & -38 & 54 & 9 & BA10 & Middle Frontal Gyrus & Anterior prefrontal cortex \\
\hline \multirow[t]{2}{*}{354} & 3.25 & 0.001 & 29 & -30 & 9 & BA41 & Insula & \\
\hline & & & 41 & -31 & 14 & BA41 & $\begin{array}{l}\text { Superior Temporal } \\
\text { Gyrus }\end{array}$ & Auditory cortex \\
\hline 94 & 3.23 & 0.001 & -6 & 9 & -24 & BA11 & Rectal Gyrus & Orbitofrontal area \\
\hline 54 & 3.13 & 0.001 & -53 & -8 & -25 & BA20 & Fusiform Gyrus & Ventral stream of visual processing \\
\hline 204 & 3.08 & 0.001 & 46 & 26 & -6 & BA47 & Inferior Frontal Gyrus & Pars orbitalis \\
\hline 32 & 2.98 & 0.001 & -45 & 33 & 4 & BA45 & Inferior Frontal Gyrus & Pars triangularis \\
\hline
\end{tabular}




\begin{tabular}{|c|c|c|c|c|c|c|c|c|}
\hline & & & & & & & & \\
\hline 79 & 2.97 & 0.001 & -8 & -66 & 37 & BA7 & Precuneus & Somatosensory associative cortex \\
\hline 38 & 2.94 & 0.001 & 20 & 31 & 37 & BA8 & $\begin{array}{l}\text { Middle Frontal Gyrus } \\
\text { Inferior Temporal }\end{array}$ & Frontal eye fields \\
\hline 127 & 2.94 & 0.002 & 59 & -67 & 5 & BA37 & $\begin{array}{l}\text { Gyrus } \\
\text { Superior Occipital }\end{array}$ & Fusiform gyrus \\
\hline 46 & 2.91 & 0.002 & -40 & -84 & 28 & BA19 & Gyrus & Associative visual cortex \\
\hline 40 & 2.84 & 0.002 & -17 & -2 & 10 & Lentiform nucleus & & \\
\hline 33 & 2.81 & 0.002 & -3 & -59 & 2 & Cerebellum & Culmen of Vermis & \\
\hline 64 & 2.81 & 0.002 & 63 & -26 & 35 & BA2 & Postcentral Gyrus & \\
\hline 30 & 2.81 & 0.002 & -52 & -62 & 0 & BA37 & Middle Temporal Gyrus & Fusiform gyrus \\
\hline 46 & 2.76 & 0.003 & -13 & -78 & -7 & BA18 & Lingual Gyrus & Secondary visual cortex \\
\hline NEG & VE C & ORRELA & TIOI & with & gait & subscore (UPDRS & & \\
\hline 310 & 3.94 & $<0.001$ & -37 & 20 & 16 & BA13 & Insula & \\
\hline 351 & 3.62 & $<0.001$ & 16 & 13 & 39 & BA32 & Cingulate gyrus & Dorsal anterior cingulate cortex \\
\hline & & & 12 & -4 & 41 & BA24 & Cingulate Gyrus & Ventral anterior cingulate cortex \\
\hline & & & 11 & 36 & 19 & BA32 & $\begin{array}{l}\text { Anterior Cingulate } \\
\text { Superior Temporal }\end{array}$ & Dorsal anterior cingulate cortex \\
\hline 509 & 3.52 & $<0.001$ & -61 & -30 & 16 & BA42 & Gyrus & Auditory cortex \\
\hline 145 & 3.49 & $<0.001$ & -43 & -28 & 38 & BA40 & Inferior Parietal Lobule & Supramarginal gyrus \\
\hline 828 & 3.49 & $<0.001$ & -42 & -4 & 31 & BA6 & Precentral Gyrus & $\begin{array}{l}\text { Premotor cortex and supplementary } \\
\text { motor area }\end{array}$ \\
\hline & & & -51 & -6 & 48 & BA4 & Precentral Gyrus & \\
\hline 289 & 3.48 & $<0.001$ & 44 & -25 & 4 & BA22 & $\begin{array}{l}\text { Superior Temporal } \\
\text { Gyrus }\end{array}$ & Primary auditory cortex \\
\hline & & & 38 & -26 & 14 & BA13 & Insula & \\
\hline 299 & 3.43 & $<0.001$ & -13 & 5 & 42 & BA24 & Cingulate gyrus & Ventral anterior cingulate cortex \\
\hline 161 & 3.32 & $<0.001$ & 44 & 16 & 25 & BA46 & Middle Frontal Gyrus & Dorsolateral prefrontal cortex \\
\hline 103 & 3.28 & 0.001 & 34 & -44 & 31 & BA40 & Parietal lobe, Sub-Gyral & Supramarginal gyrus \\
\hline 110 & 3.24 & 0.001 & -14 & 54 & 24 & BA9 & Superior Frontal Gyrus & Dorsolateral prefrontal cortex \\
\hline & & & -20 & 57 & 15 & BA10 & $\begin{array}{l}\text { Superior Frontal Gyrus } \\
\text { Superior Temporal }\end{array}$ & Anterior prefrontal cortex \\
\hline 323 & 3.23 & 0.001 & 62 & -13 & 6 & BA22 & Gyrus & Primary auditory cortex \\
\hline & & & 55 & -5 & 13 & BA43 & Precentral Gyrus & \\
\hline 277 & 3.19 & 0.001 & -56 & -20 & -14 & BA21 & $\begin{array}{l}\text { Middle Temporal Gyrus } \\
\text { Superior Temporal }\end{array}$ & Middle Temporal Gyrus \\
\hline & & & -51 & -12 & -8 & BA22 & Gyrus & Primary auditory cortex \\
\hline 49 & 3.16 & 0.001 & -43 & 43 & 21 & BA10 & $\begin{array}{l}\text { Middle Frontal Gyrus } \\
\text { Superior Temporal }\end{array}$ & Anterior prefrontal cortex \\
\hline 120 & 3.04 & 0.001 & 68 & -43 & 16 & BA22 & Gyrus & Primary auditory cortex \\
\hline 84 & 3.02 & 0.001 & -9 & 28 & 33 & BA9 & Medial Frontal Gyrus & Dorsolateral prefrontal cortex \\
\hline 57 & 2.95 & 0.002 & -32 & -20 & -20 & Hippocampus & Parahippocampal Gyrus & \\
\hline 34 & 2.92 & 0.002 & 33 & -65 & 57 & BA7 & Superior Parietal Lobule & Somatosensory Association Cortex \\
\hline 51 & 2.91 & 0.002 & 47 & 35 & 33 & BA9 & Middle Frontal Gyrus & Dorsolateral prefrontal cortex \\
\hline 41 & 2.90 & 0.002 & -52 & -35 & -11 & BA20 & Middle Temporal Gyrus & Ventral stream of visual processing \\
\hline 30 & 2.90 & 0.002 & 38 & -30 & -22 & BA36 & Limbic lobe & Parahippocampal Gyrus \\
\hline 38 & 2.84 & 0.002 & 20 & -85 & 12 & BA18 & Middle Occipital Gyrus & Secondary visual cortex \\
\hline 50 & 2.81 & 0.002 & 44 & 1 & 54 & BA6 & Middle Frontal Gyrus & $\begin{array}{l}\text { Premotor cortex and Supplementary } \\
\text { motor area }\end{array}$ \\
\hline 49 & 2.75 & 0.003 & -24 & 22 & -6 & BA13 & Insula & \\
\hline
\end{tabular}


- Freezing of gait was related to hypometabolism of premotor area during actual gait

- Freezers presented a hypermetabolism of posterior parietal cortex during gait

- Parietofrontal network was involved in freezing phenomenon

- Basal ganglia overactivation during gait was observed in freezers patients

- The balance between external and internal signals may fail during freezing 